\title{
LOS DILEMAS DEL JUEZ DE FAMILIA*
}

\author{
THE DILEMMAS OF THE FAMILY JUDGE
}

\author{
Claudio Fuentes Maureira**
}

\begin{abstract}
RESUMEN: La presente investigación se propone identificar y caracterizar aquellos problemas que actualmente aquejan a los jueces de familia en el cumplimiento de los diversos roles que la ley 19.968 les asigna. Para lo anterior el autor hace uso de métodos empíricos, específicamente el uso de entrevistas en profundidad con jueces y abogados especializados en el área de familia de tres regiones del país. Las entrevistas permitieron identificar algunos de los problemas que hoy afectan a los jueces de familia, los cuales surgen cuando estos interactúan con otros participantes del sistema de familia. Así, los jueces presentan dificultades al momento de entrevistar niños, cuando lidian con partes que no tienen abogado, al dirigir audiencias y en el curso de su interacción con abogados particulares. Posteriormente el artículo reflexiona acerca de los principales rasgos y las potenciales causas de estos problemas.
\end{abstract}

Palabras clave: Jueces de familia, Audiencias, Derecho de familia.

ABSTRACT: The objective behind this research is to identify and characterize the problems that today affect the family judges in the course of fulfilling the different roles that law 19.968 assigns to them. For this purpose the author makes use of empirical research methods, specifically semi-structure interviews with Family Judges and Family Lawyers from three regions of the country. The interviews allowed to identify some of the problems that family judges face today, which take place during their interaction with other participants of the family justice system. Indeed, Family Judges face a series of obstacles when they have to interview children, deal with self-represented parties, while conducting hearings and in the course of their interaction with private lawyers. Later on the paper reflects on the main features of these difficulties and their possible causes.

Key words: Family judges, Hearings, Family law.

\section{INTRODUCCIÓN}

En el segundo semestre de 2005 los tribunales de familia abrieron sus puertas. El objetivo detrás de estos fue la creación de un foro judicial exclusivamente dedicado a causas de familia, bajo la premisa de que las particularidades de dichos conflictos lo requerían para su adecuada resolución ${ }^{1}$.

\footnotetext{
Profesor de Derecho Procesal e Investigador, Facultad de Derecho, Universidad Diego Portales. Abogado y Magíster en Derecho por la Universidad Diego Portales. Master of Science of Law, Stanford University. Dirección postal: Av. República 105, Santiago 8320000. Correo electrónico: claudio.fuentes@mail.udp.cl

" Agradezco a mis colegas de la Facultad de Derecho de la Universidad Diego Portales, profesoras Lidia Casas, Paula Correa, Leonor Etcheverry, Ester Valenzuela y Macarena Vargas, por los comentarios a versiones preliminares de este documento. Igualmente agradezco al profesor de la Universidad Católica de Santísima Concepción Ramón García Odgers por sus sugerencias y comentarios. Obviamente todo error en la presente publicación es de mi exclusiva responsabilidad.

1 Biblioteca del Congreso Nacional de Chile (2005) p. 6.
} 
Pues bien, no es novedad para la comunidad jurídica chilena que los tribunales de familia tuvieron un inicio tormentoso. Las largas filas que rodeaban los juzgados de familia ubicados en la calle San Antonio, en el centro de Santiago, se volvieron el símbolo de una justicia que se encontraba en problemas; los tribunales se vieron rápidamente sobrepasados por una demanda de sus servicios que superó todos los cálculos iniciales. La situación se vio incrementada por la existencia de un diseño procedimental poco flexible y por un proceso de implementación deficiente ${ }^{2}$.

Más de cinco años tuvieron que pasar para que los tribunales de familia pudieran estabilizarse. En buena medida esto fue el resultado de diversas iniciativas por parte del Ministerio de Justicia y del propio Poder Judicial, destinadas a mejorar la capacidad del sistema de procesar su carga de trabajo. Empero, las mejoras en aspectos de gestión vinculados al sistema no deben llevarnos a pensar que la justicia de familia ha puesto fin a todos sus problemas.

Así, diversos estudios llevados a cabo en los últimos años dan cuenta de que la justicia de familia se encuentra aún aquejada por problemas de distinta índole, muchos de los cuales están vinculados al desarrollo de prácticas y métodos de trabajo ${ }^{3}$. Se hace necesario para mejorar el funcionamiento de la justicia de familia no solo la identificación de los actuales problemas que la aquejan, sino también su adecuada caracterización, con el fin de diseñar vías de solución efectivas.

Los diversos estudios existentes tienden a focalizarse en el funcionamiento general del sistema de familia o en aspectos puntuales de su funcionamiento ${ }^{4}$, mas ninguno de ellos ha pretendido entender con mayor profundidad los diferentes problemas que afectan a los distintos actores que participan en la justicia de familia, quienes finalmente son los que inciden en el funcionamiento del sistema día a día. En este sentido, obtener una mayor comprensión de los problemas específicos que los afectan, en especial de algunas de las prácticas que desarrollan y el porqué de estas, se vuelve fundamental a la hora de intervenir con el fin de mejorar el funcionamiento del sistema. Esta comprensión se constituye así como el objetivo general del presente estudio.

No cabe la menor duda que uno de los principales actores de la justicia de familia, sino el más importante, es el juez de familia. Esto se debe a que es este quien debe materializar en la práctica los diversos objetivos del legislador al momento de diseñar la ley de tribunales de familia. Así, basta observar el diverso articulado de la ley para concluir que es el juez de familia el encargado de garantizar el interés superior del niño ${ }^{5}$, es el responsable por ahorrar recursos al sistema al tener que filtrar la prueba asegurando que esta sea pertinente ${ }^{6}$, es el responsable de determinar la ocurrencia de los hechos ${ }^{7}$, la facilitación de acuerdos ${ }^{8}$, entre otros.

\footnotetext{
2 Lidia Casas et al. (2006) pp. 5-9.

3 Véase entre otros Fuentes, Marín y Ríos (2010).

4 Entre los primeros destacan Silva et al. (2007), Azocar, Casas y Vargas (2008) y Fuentes, Marín y Ríos (2010). Entre los estudios de contenido específico destacan: Correa y Vargas (2011) y Casas, Riveros y VarGAS (2012).

5 Ley 19.968 de 30 de agosto de 2004, Arts. 16, 19, 20, 41, entre otros.

6 Ley 19.968 (30/8/2004), Arts. 28, 47 y 61.

7 Ley 19.968 (30/8/2004), Arts. 63 y 65.

8 Ley 19.968 (30/8/2004), Arts. 9, 14 y 61.
} 
Debido a que su posición los obliga a desarrollar diversos roles y la trascendencia que estos tienen en el funcionamiento general del sistema, es que se vuelve necesario identificar y caracterizar al menos algunos de los problemas de desempeño que los jueces de familia enfrentan regularmente al momento de realizar las actividades que el legislador exige de ellos. Es este el objetivo específico de la presente investigación.

Se ha optado entonces por un enfoque que se centra en entender las dinámicas operativas del sistema de justicia de familia, desde la perspectiva del rol que cabe a los jueces en este. Para ello, y desde una perspectiva metodológica, el presente artículo se sirve de entrevistas en profundidad con jueces de familia y abogados especializados en el área, con el fin de identificar y describir algunos de los obstáculos que los primeros enfrentan al momento de cumplir con sus respectivas funciones.

El enfoque y la metodología previamente mencionada permiten al lector comprender desde un inicio que este no se trata de un trabajo dogmático o un análisis jurisprudencial. Se trata más bien de un trabajo que posiblemente se enmarca en aquella corriente que en derecho comparado se conoce como law and society ${ }^{9}$, la cual mediante la utilización métodos provenientes de las ciencias sociales pretende enriquecer la comprensión del derecho, mediante el estudio de cómo este funciona en la práctica ${ }^{10}$.

Para los fines previamente explicitados el presente documento se divide en 4 secciones además de esta introducción y las conclusiones. En la primera se explicará la metodología de investigación implementada, dando cuenta de sus beneficios y limitaciones. En la segunda se contextualizará el funcionamiento de la justicia de familia hasta la actualidad. En la tercera sección se presentarán los principales descubrimientos que el uso de la metodología ha permitido. En la cuarta sección se presentarán algunas reflexiones y comentarios sobre la información obtenida.

\section{METODOLOGÍA Y FUENTES DE INFORMACIÓN}

Para entender la realidad de los jueces de familia el escenario ideal sería presenciar el desarrollo de su trabajo, mediante la observación directa de audiencias ${ }^{11}$. Lograr lo anterior es muy difícil en el actual sistema de tribunales de familia, tal como se ha reportado en otros estudios. Estos tribunales no presentan la infraestructura ni la cultura de permitir que terceros ajenos al conflicto jurídico en cuestión puedan asistir con facilidad y presenciar una adecuada cantidad de audiencias ${ }^{12}$.

\footnotetext{
9 Véase entre otros Fix-Fierro, Friedman y Pérez-Perdomo (2003).

10 Uno de los trabajos seminales de esta corriente es el del profesor de la Universidad Wisconsin, Stewart Macaulay. En dicho artículo el profesor entrevistó a más de 60 abogados y dueños de negocios en la ciudad de Madison con el fin de determinar qué tanto peso estos daban a la regulación contractual en sus procesos de negociación y cumplimiento de sus acuerdos comerciales. MACAULAY (1985).

11 Véase en este sentido los trabajos de Darbyshire (2011) y Eekelaar y Maclean (2013).

12 Véase Fuentes, Marín y Ríos (2010) pp. 432-437. Tal como da cuenta dicho estudio, acceder a audiencias en tribunales de familia supone un proceso engorroso y lento en donde el observador debe superar múltiples barreras; desde el guardia que inquisitivamente pregunta por qué uno desea ver audiencias sin ser parte en el proceso, pasando por el funcionario del mesón que cuestiona cualquier interés de un tercero en verlas, hasta los mismos jueces, muchos de los cuales a pesar de que la ley establece explícitamente la publicidad como regla
} 
Dado lo anterior se ha optado por una alternativa metodológica la cual se basa en el uso de entrevistas semiestructuradas con operadores del sistema de justicia ${ }^{13}$. El objetivo ha sido entrevistar a operadores del sistema con años experiencia trabajando en la justicia de familia, a través de los cuales se pueda recoger información relevante sobre su realidad. En otras palabras, se ha optado por considerar a los operadores del sistema de justicia como testigos privilegiados de su funcionamiento.

¿Pero quiénes son estos testigos privilegiados? Obviamente los primeros son los jueces de familia, aquellos que simbolizan la justicia de familia en Chile. Sin embargo, entrevistar solo a jueces de familia es un riesgo, tal cual como muestra la literatura comparada ${ }^{14}$, ya que es muy posible que estos tengan prejuicios respecto de su realidad y de su propio desempeño. Por ello es importante entrevistar otros sujetos, aquellos que presenten una perspectiva alternativa a la de los jueces, que puedan corroborar o desmentir sus afirmaciones y experiencias. Se ha escogido a los abogados de familia como aquellos que están en condiciones de proveer esta otra perspectiva. Ambos grupos de entrevistados, gracias a su experiencia, poseen no solo un conocimiento de primera mano de la realidad, sino que una comprensión profunda acerca de sus lógicas y dinámicas, viéndose todos los días las caras y desarrollando sus propias prácticas ${ }^{15}$.

Un punto a detallar es que el estudio solo contempló entrevistar abogados particulares del área de familia y no abogados de la Corporación de Asistencia Judicial. Esta omisión puede constituir una de las posibles críticas metodológicas que puede hacerse a este trabajo. La razón que justificó esta decisión radica en la experiencia previa del investigador en estudios referidos a la justicia de familia, en la cual se ha observado que dada la actual modalidad de trabajo de audiencias concentradas existe una relación de colaboración permanente

general, estiman que todas las materias de familia son reservadas, contrariando el mandato del legislador. Finalmente, tal como el estudio da cuenta, solo unos pocos jueces de familia se presentan dispuestos a ser observados mientras desarrollan su trabajo.

13 Las entrevistas semiestructuradas consisten en entrevistas basadas en una pauta previamente definida en función de los objetivos de la investigación. Con todo, dicha pauta es solo la base de la entrevista, ya que se trata de temáticas generales a discutir, alejándose de un interrogatorio detallado del entrevistado. Esto permite dirigir la entrevista a aquellos aspectos que el entrevistador considera relevantes, permitiendo al mismo tiempo que esta puede ser llevada a otras temáticas que aparezcan en el contexto de la entrevista misma. En el presente caso los jueces y abogados entrevistados fueron sujetos a una pauta de discusión, pero en muchas ocasiones estos identificaban otros aspectos relevantes que originalmente no fueron inicialmente planteados por el autor. GaínZA (2006) pp. 219-224.

14 Thomas (2006) p. 36.

15 Sería posible entrevistar a los consejeros técnicos dado que estos trabajan con los jueces diariamente, no obstante se ha optado por no entrevistarlos debido a diversas consideraciones. La razón más poderosa la constituye el hecho de que los consejeros técnicos cumplen una serie funciones que no están descritas en la ley, pero que igualmente se manifiestan en la práctica. Estas funciones van desde constituirse en escenarios informales en donde ellos filtran casos e intentan establecer (presionar) bases de un acuerdo, a un rol decisivo en determinado tipo de causas, especialmente en medidas cautelares. En este sentido, comprender e investigar el rol de los consejeros técnicos supone una labor de investigación mayor, que escapa de los límites de la presente investigación. Es posible pensar que los consejeros técnicos y su rol en la justicia de familia permiten el desarrollo de un artículo autónomo de mayor envergadura. BeNGOECHEA (2010) pp. 2-4. 
entre los jueces de familia y los abogados de la Corporación, la cual a juicio de quien escribe puede invisibilizar problemas ${ }^{16}$.

El presente estudio se focalizó en los tribunales de la Región Metropolitana y las regiones del Biobío y del Maule. Diversas razones explican esta decisión. La primera buscaba evitar la tendencia seguida en otros estudios previos de considerar únicamente la realidad santiaguina, después de todo Santiago no es $\mathrm{Chile}^{17}$.

La segunda razón dice relación con la técnica de investigación utilizada, ya que la metodología de entrevistas semiestructuradas supone contar con profesionales que estén dispuestos a ser entrevistados en profundidad, con el fin de conocer sus experiencias en detalle $^{18}$. Esto llevó a que el autor comenzara entrevistando a diversos jueces y abogados quienes estaban dispuestos a participar, para después que estos refiriesen a otros profesionales igualmente dispuestos (técnica de investigación conocida como snowballing) ${ }^{19}$. Lo último permitió contar con una serie de entrevistas de jueces y abogados de diversas regiones del país, optándose finalmente por basar la investigación en aquellas regiones en donde se contó con una mayor cantidad de abogados y jueces entrevistados.

Se consideró esta medida porque permite parcialmente hacerse cargo de la crítica válida de que las entrevistas semiestructuradas no garantizan resultados representativos. Para ello se buscó solo reportar resultados de aquellas regiones en donde se contó con al menos 3 profesionales entrevistados. Asimismo, al entrevistar a más de un profesional por región se identificó visiones contrapuestas y compartidas sobre una misma realidad, lo que estima el autor da mayor valor a la entrevista. Es importante entonces que el lector tenga en mente que al final las experiencias relatadas en el presente estudio solo representan a aquellos que

16 Al respecto el estudio de Fuentes, Marín y Ríos señala "Las razones que explican que en el sistema de audiencias concentradas se termine en la primera audiencia un porcentaje importante de causas pueden ser descompuestas en dos grandes factores. (...) Pensamos que esta situación se ha originado debido al nuevo rol del abogado CAJ, que lo deja en una situación intermedia entre parte y funcionario del tribunal, al generar una dinámica de trabajo más cercana con los jueces y funcionarios, lo que a su vez genera vínculos de confianza"(el destacado es propio). Fuentes, Marín y Ríos (2010) p. 389.

La relación de confianza entre los jueces de familia y los abogados CAJ se da en el contexto en que ambos actores se ven todos los días en los tribunales, siendo lo que en doctrina se conoce como "repeat player". Más importante aún, el estudio citado da cuenta de que existe una alineación de los intereses de los abogados CAJ y los jueces en sus esfuerzos conjuntos por terminar los casos en primera audiencia. Esta dinámica se daría cuando el abogado CAJ previo a la audiencia intenta llegar a un acuerdo y cuando esto no es posible le informa al juez por qué el abogado de la contraria se opone, para que sea el juez quien intente nuevamente persuadir (¿presionar?) al abogado particular.

Esta alineación de intereses hace que los jueces y abogados CAJ generen prácticas de colaboración que en muchas ocasiones se traducen en una alianza respecto de la cual el abogado particular no es parte. Es esta misma alianza la que permite sostener que los abogados CAJ pueden no ver o no compartir críticas que los abogados particulares presentan, ya sea porque no les ocurre a ellos por tener una relación de cercanía con el tribunal o porque dichas prácticas derechamente les benefician. Un fenómeno similar fue descrito en la reforma laboral, véase CaSAS y OlEa (2014) pp. 146-148.

17 Véase como ejemplos Silva et al. (2007) y Fuentes, Marín y Ríos (2010).

18 Las entrevistas con jueces tuvieron una extensión aproximada de 50 a 70 minutos, mientras las entrevistas con los abogados de 40 a 60 minutos.

19 Bryman y Teevan (2005) pp. 227-228. 
las dieron y si bien es posible que algunas de ellas puedan reflejar problemas más generales, esto último la metodología empleada no permite afirmarlo concluyentemente.

Para finalizar esta sección es importante dar cuenta en detalle de los sujetos entrevistados. La investigación se realizó en base a 12 entrevistas en profundidad, 7 jueces y 5 abogados de familia de las tres regiones mencionadas ${ }^{20}$. La siguiente tabla individualiza los sujetos entrevistados, indicando su respectivo rol, ubicación geográfica y la extensión de su experiencia en años vinculado a la justicia de familia.

TABLA 1:

JUECES Y ABOGADOS ENTREVISTADOS SEGÚN SU EXPERIENCIA EN EL SISTEMA DE FAMILIA

\begin{tabular}{|l|l|l|}
\hline \multicolumn{1}{|c|}{$\begin{array}{c}\text { Sujeto } \\
\text { entrevistado }\end{array}$} & \multicolumn{1}{|c|}{ Región } & \multicolumn{1}{c|}{$\begin{array}{c}\text { Tipo de experiencia en el sistema de familia } \\
\text { (años de experiencia) }\end{array}$} \\
\hline Abogado 1 & Región Metropolitana & $\begin{array}{l}\text { Desde el año 2006, 100\% de su práctica dedicada a casos de } \\
\text { familia (8). }\end{array}$ \\
\hline Abogado 2 & Región Metropolitana & $\begin{array}{l}\text { Desde el año 2005, más de un 90\% de su práctica dedicada } \\
\text { al área de familia (9). }\end{array}$ \\
\hline Abogado 3 & Región Biobío & $\begin{array}{l}\text { Desde el año 2005, más de un 70\% de su práctica dedicada } \\
\text { a área de familia (9). }\end{array}$ \\
\hline Abogado 4 & Región Biobío & Desde el año 2005 100\% dedicada a casos de familia (9). \\
\hline Abogado 5 & Región Metropolitana & $\begin{array}{l}\text { Desde el año 2010, 60\% de su práctica dedicada a casos de } \\
\text { familia (4). }\end{array}$ \\
\hline Juez 1 & Región Metropolitana & Juez de familia desde 2009 (5). \\
\hline Juez 2 & Región Metropolitana & Juez de familia desde 2006 (8). \\
\hline Juez 3 & Región Maule & Juez de familia desde 2006 (8). \\
\hline Juez 4 & Región Biobío & Juez de familia desde 2005 (9). \\
\hline Juez 5 & Región Biobío & Juez de familia desde 2006 (8). \\
\hline Juez 6 & Región Maule & Juez de familia desde 2005 (9). \\
\hline Juez 7 & Región Maule & Juez de familia desde 2006 (8). \\
\hline
\end{tabular}

Finalmente, los resultados provisorios de este trabajo fueron presentados en una reunión de trabajo llevada a cabo en la Facultad de Derecho de la Universidad Diego Portales, en el cual profesores e investigadores ligados al área de familia sometieron a discusión los resultados obtenidos ${ }^{21}$.

\section{CONTEXTO: EL DIFÍCIL CAMINO DE LA JUSTICIA DE FAMILIA}

Como es sabido la implementación de los tribunales de familia comenzó el segundo semestre de 2005 y desde su inicio presentó diversos problemas. De hecho estos se manifestaron desde el primer día en que abrieron sus puertas, cuando extensas filas de personas rodeaban los tribunales esperando ser atendidos. Los números de la justicia de familia re-

\footnotetext{
20 La mayoría de las entrevistas tuvieron lugar en los meses de enero a marzo del año 2014. Un segundo grupo de entrevistas, incorporando otros abogados litigantes, tuvo lugar durante el mes de agosto del mismo año.

21 La reunión de discusión contó con la participación de las profesoras e investigadoras Lidia Casas, Paula Correa, Leonor Etcheberry, Ester Valenzuela y Macarena Vargas.
} 
flejaban lo complejo de la situación; una vez que una demanda era presentada la audiencia preparatoria nunca tenía lugar antes de 9 a 12 meses y una vez realizada esta, la audiencia de juicio no tenía lugar en menos de 5 meses, provocando que incluso materias en donde no había real controversia tomaran más de un año en ser resueltas ${ }^{22}$. Ante este escenario rápidamente los usuarios del sistema, los expertos y los políticos empezaron a hablar de la crisis de la justicia de familia.

Dos cursos de acción fueron tomados para resolver este problema. El primero fue la creación de una mesa técnica en la cual jueces, abogados y expertos participaron, la cual concluyó en 2008 con la publicación de una ley con modificaciones al procedimiento de familia. La Corte Suprema igualmente decidió crear la Unidad de Apoyo a la Justicia de Familia, dirigida por el Ministro Héctor Carreño, con la finalidad de realizar un diagnóstico y desarrollar medidas administrativas para mejorar el funcionamiento del sistema. La más famosa de estas medidas fue la llamada Acta 98-2009, la cual contempló una serie de herramientas de gestión y la creación de una tipología de audiencias, que introdujo la necesaria flexibilidad en la tramitación de causas dentro del sistema ${ }^{23}$.

Después de un proceso no exento de controversias, las modificaciones legales introducidas mediante la ley 20.286 y las medidas administrativas tomadas, incluidas el acta 98 y sus predecesoras, llevaron a que a finales del año 2009 el Ministro Carreño en la cuenta pública de la unidad de apoyo indicará que "la justicia de familia se había normalizado" ${ }^{24}$, al mejorarse considerablemente la capacidad del sistema de procesar las causas a efectos de agendarlas en tiempos muy breves ${ }^{25}$.

Superados mayoritariamente los temas de gestión comenzó un nuevo período de trabajo para la justicia de familia, en la cual los aspectos de calidad de la justicia debían ser resueltos $^{26}$. En la literatura disponible solo existen dos investigaciones generales que profundizan en aspectos de calidad asociados al funcionamiento general de la justicia de familia ${ }^{27}$. Ambas investigaciones parecen indicar que las mejoras en gestión no habrían permitido una mejora sustancial en este otro tipo de aspectos.

El primer estudio realizado por la Facultad de Derecho de la UDP y CEJA el 2010 confirmó las mejoras en el procesamiento de causas a las que aludía el Poder Judicial, pero igualmente detectó el surgimiento de ciertas prácticas problemáticas tanto por parte de los jueces, como de los abogados litigantes ${ }^{28}$. Así, el estudio detectó una falta de comprensión por parte de los jueces y los abogados acerca de uno de los principales valores de la reforma:

22 CASAS et al. (2006) p. 15 y SiLVA et al. (2007) p. 173.

23 Para una descripción completa de los problemas de gestión de mayor relevancia que aquejaban a los tribunales de familia y las medidas tomadas para solucionarlos véase GARCía (2012) pp. 156 y ss.

24 Corte Suprema de Chile (2009) p. 19.

25 A este respecto en el informe emitido por el director de la unidad de apoyo de la justicia de familia del año 2012 se señala: "el sistema de justicia de familia se encuentra totalmente normalizado en todo el territorio nacional (...)". CARREŃO (2013) p. 1.

${ }^{26}$ En este sentido el Ministro Sr. Héctor Carreño indica: "Regularizada la situación de los tribunales a lo largo del país, hoy se piensa en la calidad". CARreño (2012) p. 9.

27 Aunque sí existen algunas investigaciones que dan cuenta de problemas específicos, entre ellas CorreA y VARGAS (2011).

${ }^{28}$ Fuentes, Marín y Ríos (2010) pp. 409-440. 
la necesidad de presentar la prueba frente a los tribunales y permitir a las partes su control mediante el contrainterrogatorio. Esto se volvía manifiesto cuando se analizaba la situación de los peritos de organismos públicos, los cuales eran excusados de declarar frente al tribunal, incluso contra la solicitud de las partes, transformando su informe escrito un medio de prueba prácticamente inescrutable a estas debido a que no era posible cuestionar su metodología o resultados sin poder interrogar directamente al perito ${ }^{29}$.

Asimismo, la práctica demostró que la audiencia preparatoria no cumplía adecuadamente con el propósito de preparar el desarrollo del juicio oral. Esto se verificaba debido a que las partes solamente anunciaban la prueba que usarían, pero nunca entregaban información detallada para permitir, por un lado, que la contraria se enterara adecuadamente del contenido de la evidencia y, por otro, se impedía la realización de un examen detallado acerca de la pertinencia de la prueba ofrecida. Gracias a esta práctica la audiencia preparatoria en familia se caracterizaba por la carencia de un debate sofisticado acerca de la prueba ofrecida, constituyéndose en un escenario formal, que no garantizaba el derecho al contradictorio.

Un segundo estudio fue realizado por el Centro de Estudios de Justicia de las Américas (CEJA) el año 2013, esta vez analizando las reformas procesales civiles en diversos países del continente, incluyendo los tribunales de familia chilenos. Dicho estudio en el cual se observaron algunas audiencias, mostró que prácticas problemáticas persisten en dicha judicatura. Entre estas destacan problemas en la dinámica de la audiencia de juicio al momento de lidiar con diversos medios de prueba.

Así, respecto de la prueba documental, esta en vez de presentarse al servicio de un relato, mediante testigos que reconocieran dichos documentos y dieran referencias de ellos, eran simplemente leídos todos juntos, sin mayor detalle y utilidad. Se detectó igualmente que en el caso de la prueba testimonial que en la mayoría de las ocasiones los abogados no tenían claridad acerca de qué dirían sus propios testigos y en consecuencia ninguna idea de qué preguntarles ${ }^{30}$. Igualmente los problemas asociados a la audiencia preparatoria previamente detectados se mantenían vigentes ${ }^{31}$.

El estudio en cuestión da cuenta que el estado actual de la justicia civil reformada, incluida la justicia de familia en Chile, indicando que: "Pareciera que esta falta de aprovechamiento de la audiencia como una instancia de real análisis de la prueba pasa por distintos niveles de desafíos no resueltos todavía por los sistemas orales estudiados (...) pareciera existir una cierta conformidad con el funcionamiento actual de los sistemas y pocos esfuerzos por sistematizar y crear modelos concretos que desde la capacitación y el seguimiento vayan instalándose en los juzgados. Esto además coincide (y probablemente es

\footnotetext{
29 La regulación de cuando el perito debe comparecer en familia ha dado origen a diversos problemas, especialmente por una inconsistencia normativa entre el artículo 45 y el artículo 49 de la ley 19.968, no siendo claro si las partes deben pedir en cada oportunidad la comparecencia del perito, siendo por tanto la regla general el informe pericial, o si la regla general es la comparecencia y el perito solo puede ser excusado explícitamente por las partes de comparecer. Según Mauricio Duce la noción predominante en familia de que la prueba pericial constituye el informe constituye una práctica que contradice el cambio de paradigma que la regulación de la prueba pericial ha sufrido en nuestro país. Véase Duce (2013) pp. 114 y ss.

30 Ríos (2013) pp. 110 y 111.

31 Ríos (2013) pp. 128-130.
} 
parte del mismo problema) con una falta de comprensión de los roles de los actores involucrados, fundamentalmente en cuanto a qué consiste en la práctica la llamada "dirección del proceso" que es responsabilidad de los tribunales y sobre un método concreto que ayude a los litigantes a comprender qué información es la que deben poner a su consideración y cómo esta debe ser ordenada y presentada" ${ }^{2}$.

Como se puede ver, la investigación CEJA 2013 concluye que existen diversos problemas en las reformas a la justicia civil en América Latina, la cual incluye a nuestra reforma a los tribunales de familia. Se observan falencias vinculadas a los actores mismos, quienes manifiestan una falta de comprensión de sus roles y muchas veces de cómo hacer su trabajo. Esto además afectaría el adecuado funcionamiento de ciertas instituciones procesales, las cuales no estarían operando a toda su potencialidad. Se trata de áreas de disfuncionalidad que dan cuenta que la implementación de los tribunales de familia está lejos de concluir y que aún hay mucho por mejorar.

\section{RESULTADOS}

\subsection{LA SILLA MUSICAL}

Como es sabido el paradigma del juez de familia ha sido objeto de una transición cultural importante. Al comienzo de los tribunales de familia muchos jueces, especialmente aquellos que venían de los tribunales de menores, pensaron que se comportarían de la misma manera que antes, controlando en buena medida sus horarios de trabajo. Esta situación no es la que ocurre hoy y parece que los jueces de familia han aceptado, no sin problemas, que muchas de sus prerrogativas previas ya no aplican.

Como consecuencia, y de forma contraria a lo que ocurre en otros países, los jueces de familia chilenos tienen poca autonomía respecto de su agenda de trabajo. En el caso de Chile la introducción del administrador de tribunal en los sistemas reformados cooptó este poder con el fin de asegurar que todos tuvieran una carga de trabajo similar y que trabajaran de forma más eficiente ${ }^{33}$. De hecho, los poderes del administrador de tribunal en esta materia crecieron en gran medida gracias a la famosa Acta 98, la cual impactó en el desarrollo de procesos de agendamiento más eficientes mediante la introducción de una tipología de causas, las cuales permitían destinar una rutina interna distinta a las causas en función de la complejidad probatoria, el tipo de prueba (documental o testimonial) y otros criterios $^{34}$.

Dado lo anterior no fue sorpresa descubrir al momento de entrevistar a los jueces, incluso aquellos de diversas regiones, que cuando se les pedía que describieran su trabajo cotidiano, estos en general presentaban un panorama muy similar. Así, estos indicaban que trabajaban de lunes a viernes, siendo asignados semanalmente a determinados tipos de salas en función de la complejidad de la causa y la materia ${ }^{35}$.

\footnotetext{
32 Ríos (2013) p. 122.

33 Biblioteca del Congreso Nacional de Chile (2005) p. 11.

34 Riego (2013).

35 Acta 98-2009 de 20 de mayo de 2009, artículo 15 letra c), intitulado Centralización.
} 
Por ejemplo, en el caso de algunos tribunales de la Región del Maule, estos se dividen en salas destinadas a conocer exclusivamente una o más materias relacionadas, dividiéndose en salas de violencia intrafamiliar, alimentos menores, casos de mediana a alta complejidad y ejecución. Esto supone que una semana el juez preside solo audiencias de alimentos, a la semana siguiente casos más complejos y así sucesivamente ${ }^{36}$.

Una situación similar ocurre en los tribunales de la Región Metropolitana y del Biobío, existiendo algunas diferencias puntuales. Por ejemplo, en los tribunales de la Región Metropolitana hay un centro de medidas cautelares, de dedicación exclusiva, en donde algunos jueces solo ven ese tipo de materias. Asimismo, en el caso de los tribunales del Biobío, estos se dividen semanalmente, pero el tipo de salas que existe varía y también la cantidad de semanas, estando en algunas salas dos semanas, mientras que en otras una.

Lo importante para efectos de este documento es que en general los jueces de familia trabajan de una forma similar, mediante la rotación entre diversas salas de audiencias lo cual les permite lidiar regularmente con una serie de materias y conflictos. Esto implica que los jueces de familia en general ven todo tipo de casos y materias, gracias al sistema de agendamiento de los tribunales.

\subsection{DesAFíOS y PROBLEMAS}

Las entrevistas realizadas con jueces de familia y abogados permiten identificar una serie de situaciones que afectan el trabajo de los jueces que son de común ocurrencia. Como se verá estas situaciones disfuncionales ocurren en el contexto en el cual el juez interactúa con otros participantes del sistema de tribunales de familia.

\section{a) El juez tirano y el abogado incompetente}

Tanto los jueces de familia como los abogados reconocen como un primer problema la tensa relación que existe entre ambos profesionales en el contexto de los juicios de familia. Ambos operadores reconocen que esta tensión afecta sus respectivas funciones laborales. En esta sección se explora los rasgos principales de esta relación y sus consecuencias en las labores desempeñadas por ambos intervinientes.

La perspectiva de los abogados privados en referencia a la relación que tienen con los jueces de familia se grafica en las palabras del Abogado 2: "La mala relación con los jueces es un problema que persiste fuertemente hasta el día de hoy. Se traduce en una dinámica de poder, en donde el juez sabe que él es el poderoso. Estos no te permiten siquiera argumentar porque es necesario más tiempo. En este sentido me parece que los jueces cometen un grave error (...) hay veces que la pelea no vale pena, en esos casos mala suerte, abandono no más".

Los dichos del Abogado 2 muestran que entre los abogados de familia existe la idea de que los jueces abusan de su poder. La forma más elemental de abuso consiste en una postura inaccesible por parte de los jueces, en la cual los dichos y argumentos de los aboga-

\footnotetext{
36 La descripción presentada es bastante vaga. Esto se debe a que todos los jueces entrevistados solicitaron mantener sus identidades bajo reserva. Para ello se optó por hablar de tribunales regionales y omitir información que permita identificarlos, como sería aquella que permite individualizar de qué tribunal en particular estos provienen mediante la identificación particular de sus respectivos sistemas de agendamiento.
} 
dos no son escuchados, siendo mayormente ignorados, muchas veces privándolos siquiera de la oportunidad de intervenir para hacerlos cambiar de opinión. La actitud de los jueces de familia provoca en los abogados particulares sentimientos de irrelevancia y frustración, al hacer patente a estos que lo único que importa es la posición de los primeros.

La información que los abogados proveen refiere a otras formas en que este comportamiento abusivo toma lugar, conductas que el Abogado 3 califica como déspota. El Abogado 3 ha estado vinculado a la justicia de familia desde los antiguos tribunales de menores, siendo hoy un litigante regular en los tribunales de la Región del Biobío. Según su experiencia lidiando con jueces de familia, muchos de ellos actúan de forma déspota al comportarse en innumerables situaciones ignorando expresamente el texto legal, actuando como si la ley no fuese un límite para ellos. El entrevistado señala que los jueces de familia tienen demasiado poder en el contexto del procedimiento de familia y que el uso de ese poder es excesivo, muchas veces pasando a llevar los derechos de las partes ${ }^{37}$.

Curiosamente la opinión del Abogado 3 es apoyada por la Jueza 1. Ella señala que no se comporta de manera abusiva, pero reconoce que algunos de sus colegas sí lo hacen. Señala que está al tanto de que otros jueces de familia efectivamente imponen a las partes decisiones que no tienen sustento legal o que van más allá de los límites de la ley, creando o inventando excepciones que el mismo texto legal no admite. Más aún, todos los jueces entrevistados en el contexto de esta investigación asumen una posición interesante respecto de esta situación. Ninguno de ellos reconoce que se comporta de forma abusiva respecto de los abogados, pero al mismo tiempo todos ellos reconocen que conocen o al menos han escuchado que otros jueces sí lo hacen, describiéndolos como jueces que actúan por sobre la ley.

El comportamiento abusivo de algunos jueces de familia se manifiesta incluso en situaciones extremas. Según los jueces y abogados entrevistados estas situaciones cada día son menos comunes, pero aun siguen ocurriendo. Entre estas situaciones extremas los abogados 2 y 3 identifican un uso agresivo del lenguaje, incluyendo gritos ${ }^{38}$. Nuevamente esta experiencia es apoyada por uno de los jueces entrevistados, el Juez 2 de la Región Metropolitana. Este juez afirma que ha detectado estas conductas abusivas cuando ha escuchado los audios de sus colegas en audiencia, contexto en el cual ha oído gritos de los jueces a los abogados y otras formas de mal trato, como un tono prepotente al momento de dirigirse hacia estos.

\footnotetext{
37 La opinión expresada por el Abogado 3 permite vincular las actuaciones abusivas de algunos jueces de familia con el debate doctrinario acerca de los poderes del juez. Es posible pensar que en un sistema procesal en donde el legislador le entrega al juez una serie de atribuciones que en otros modelos procesales no tienen, favorece el surgimiento de una actitud prepotente y de abuso, sintiéndose más legitimado para comportarse de tal forma. Más allá de lo anterior, el debate interminable acerca de los poderes del juez no es una cuestión que interese a este documento. Para más información al respecto véase HuNTER (2011).

38 Muy vinculado con el desarrollo de tratos inapropiados por parte de los jueces a los abogados está la práctica de apagar el audio. Algunos abogados entrevistados dan cuenta de que algunos audios de las audiencias no dan cuenta en la mayoría de los ocasiones de este tipo de malos tratos debido a que existe la práctica de ordenar al "acta" que apague el audio, momento en el cual se da una audiencia dentro de otra audiencia. Este sin embargo no parece ser solo un problema de familia, existiendo cierta información que da cuenta del hecho en laboral. Se trata de un tema que en el futuro debe ser investigado en profundidad.
} 
Como consecuencia natural de estas formas de maltrato los abogados entrevistados creen que los jueces de familia no entienden el rol que estos están llamados a cumplir, especialmente cuando se trata de defender el derecho de sus representados. De hecho el trato que los jueces proveen a los abogados los deja en una posición difícil, al verse obligados a escoger entre tolerar este comportamiento abusivo u oponerse a este, pero dañando el caso de su cliente. Al final la mayoría de los abogados entrevistados dejan de insistir, tal cual como refleja las opiniones del Abogado 2.

Con todo esto es solo un lado de la historia. El otro lado, el de los jueces, refleja otra dimensión de este problema. Existe completo acuerdo entre los jueces entrevistados respecto de un problema específico que afecta a los tribunales de familia: el bajo nivel de preparación y la mala calidad de los abogados particulares. Al respecto, los jueces de familia son lo suficientemente cuidadosos en distinguir los abogados privados de los abogados que trabajan en la Corporación de Asistencia Judicial, estos últimos siendo considerados como buenos abogados. Por el contrario, los jueces están de acuerdo en el hecho de que la mayoría de los abogados particulares no saben cómo manejar las audiencias y peor aún, usualmente llegan sin conocer el caso.

Las consecuencias de esta baja calidad y baja preparación imponen sobre los jueces una serie de problemas que afectan su trabajo, especialmente dificultades éticas y de administración del tiempo. Respecto las primeras, la opinión del Juez 4 es clara: "llega una mujer que podría haber obtenido una compensación económica en un juicio y va a quedar sin ella porque el abogado no tiene idea de lo que está haciendo. Al final uno termina subsidiando a la otra parte, sabiendo lo que significa eso, que la ley te da la posibilidad. La verdad es que llegas a un punto en que no es agradable que abiertamente estés ayudando a un abogado para evitar que se haga una injusticia”.

$\mathrm{Al}$ respecto las actitudes de los jueces de familia revelan molestia y dudas. Los jueces se manifiestan hastiados, ya que entienden que este tipo de conductas constituye una falta de respeto con el tribunal, pero más importante aún, con las propias personas. Esta es la opinión del Juez 5 de la Región del Biobío. Una posición similar es sostenida por la Jueza 6 de la Región del Maule, quien señala que la actitud de los abogados privados la molesta profundamente dado que saben que les están pagando por hacer mal su trabajo.

Los jueces también experimentan dudas sobre su actuar. Así la Jueza 6 sostiene que a ella le produce mucho pesar cuando una parte está mal representada, pero que no es su deber ayudarlas. A pesar de lo anterior la mayoría de los jueces, como el Juez 4, sostiene que enfrentan una posición difícil al ayudar a un abogado incompetente. Al final la mayoría termina ayudando a la parte mal representada, argumentando que las personas no son responsables de la falta de profesionalismo de sus abogados ${ }^{39}$.

En este contexto la Jueza 7 de la Región del Maule sostiene que son particularmente problemáticos los abogados que vienen del sistema antiguo, respecto de los cuales ella

\footnotetext{
39 Uno de los abogados entrevistados, el abogado 5, dio cuenta de un relato que apoya lo sostenido por los jueces. Al respecto indicó: "el abogado puede hacerlo bastante mal y el juez termina haciéndole la pega. Puede el abogado no cachar [sic] las normas y el juez resolverá en derecho. El juez puede corregir tu prueba, por ejemplo, he planteado un informe que no corresponde y el juez lo ha modificado (...)".
} 
termina diciéndoles qué hacer y cuándo actuar. En otros casos, como el de la Jueza 1, ella pierde rápidamente la paciencia cuando los abogados no preguntan aquello que debe ser preguntado o no ofrecen la prueba necesaria. Sostiene que en ese momento se ve forzada a intervenir y comienza a interrogar a los testigos. De hecho la Jueza 1 sostiene que de alguna forma se ve obligada a ignorar una serie de situaciones, ya que si ella hiciera valer el estándar legal para una representación de calidad, debería declarar abandonada la defensa casi el 98\% de las veces.

Las consecuencias de este problema son bien claras. Dado que la calidad de la mayoría de los abogados privados es deficiente y que estos no hacen su trabajo adecuadamente, entonces los jueces señalan que se ven forzados a intervenir y pierden buena parte de su tiempo asistiendo a los abogados, ya sea diciéndoles qué decir, qué preguntar o derechamente interrogando a los testigos. El sentimiento de los jueces de familia se grafica en la postura sostenida por la Jueza 3, quien indica que al final los abogados transfieren la responsabilidad a los jueces. Cuando los jueces los ayudan el abogado obtiene un fallo favorable, yéndose a su casa y cobrando su remuneración, pensando que hizo un buen trabajo. Por el contrario, si el juez no lo ayuda y pierde el juicio, le señala al cliente que el juez es un descriteriado.

\section{b) Diálogo de sordos}

La ley de tribunales de familia establece desde el año 2008 el requisito para las partes de encontrarse representada por abogado habilitado para el ejercicio de la profesión, con la excepción de casos de violencia intrafamiliar y medidas de protección. La razón detrás de esta distinción radica en el contexto de emergencia que este tipo de materias usualmente involucra, en las cuales requerir la contratación de un abogado puede desincentivar a las partes a presentar la denuncia o puede constituirse en un obstáculo importante que impida una respuesta oportuna por parte de las autoridades.

Más allá de la racionalidad que justifica esta distinción, la información recopilada en el contexto de entrevistas con los jueces de familia da cuenta de que esta distinción ha sido una fuente de problemas y dificultades para los jueces mismos, en el sentido de que lidiar con partes sin representación legal exige manejar un conjunto complejo de actividades, con las cuales no se sienten cómodos, como se caracterizará en las siguientes líneas.

La primera actividad que los jueces de familia deben realizar es determinar qué buscan las personas que solicitan la intervención del tribunal. La mayoría de los jueces entrevistados indican que esta tarea aparentemente básica es fuente de frustración entre los jueces y los ciudadanos que solicitan su ayuda.

En este sentido la dinámica de interacción entre el juez y la parte es compleja. En el caso de las partes, dado que estas no son abogado, muchas veces llegan a las audiencias con solicitudes que no son posibles de resolver a través de dicho procedimiento o llegan con expectativas que no son posibles de lograr a través de los tribunales. Un buen ejemplo de esto es explicado por el Juez 4.

El Juez 4 indicó que solo un par de días antes de que fuera entrevistado para este estudio, se encontraba presidiendo la sala que ve causas de violencia intrafamiliar. En este contexto recibió a una mujer la cual comunicó, a través de un proceso de interrogación 
por parte del juez, que ella quería divorciarse. Ante esto el Juez 4 le indicó que esto no era posible a través de este procedimiento, ya que había presentado una denuncia por VIF y no una demanda de divorcio. El Juez 4 señaló que la interrogó nuevamente sobre sus objetivos, ante lo cual la mujer solo respondió que quería que su marido cambie, frente aquello el juez le respondió que él no era un consejero de familia, que, por el contrario, es un juez y que su rol es otro.

Ahora bien, en casi todas las entrevistas que fueron llevadas a cabo para este estudio, los jueces de familia explicaron que el proceso para determinar cuál es el objetivo del ciudadano es muy complejo para ellos. En este sentido la interacción con las partes con este fin ocupa una buena parte de la audiencia y muchas veces resulta ser un diálogo entre personas que pareciera hablan idiomas distintos.

En términos generales el proceso que los jueces llevan a cabo cuando lidian con partes sin abogado se traduce en dos tareas: filtrar y comunicar. Filtrar supone que el juez debe discriminar de toda la información que la parte le provee qué es aquello que es legalmente relevante para la audiencia en cuestión. Esto supone que la mayoría de las veces los jueces deben escuchar relatos que son difíciles de seguir y de hecho estos admiten que muchas veces no entienden lo que partes les dicen y les piden ${ }^{40}$.

Una vez que el juez logra entender o cree entender lo que la persona le solicita, el juez trata de explicarle qué información es relevante y cuál no lo es. Esta es la parte del proceso que es más frustrante para los jueces, ya que más allá de sus esfuerzos por ser claros, derechamente las personas no les entienden ${ }^{41}$. Al respecto la Jueza 1 sostiene: "usualmente las personas que comparecen sin abogado se encuentran en un estado de vulnerabilidad, son personas privadas socioculturalmente (...) tienen muchos problemas al tratar de entender aquello que tú les explicas, les cuesta entender las consecuencias de las decisiones (...) si ellos no tienen representación legal entonces no puede haber verdadera justicia”.

Sin embargo, este no es el único problema que los jueces deben enfrentar. Una vez que han explicado al solicitante el objetivo de la audiencia, se vuelve importante determinar qué prueba es necesaria. Lo cierto es que, en otras materias donde las partes se encuentran asesoradas por abogados, son estos los encargados de identificar y seleccionar la prueba disponible, situación que no se da en este tipo de materias, problema que impone sobre los jueces problemas éticos y prácticos.

Un ejemplo sobre estos problemas es presentado por la Jueza 3. Ella sostiene que en este tipo de casos tiempo importante de la audiencia se va en tratar de ayudar a la parte en

\footnotetext{
40 Resulta interesante notar que parte de los problemas que los jueces de familia chilenos enfrentan al momento de lidiar con partes sin representación legal son compartidos por otros sistemas jurídicos, como por ejemplo el caso de Inglaterra y Gales: "Lo que observó fue que la participación de partes sin representación legal suponía una lucha permanente para traducir los conflictos en términos legales. A ellos les costaba identificar cuáles eran los aspectos jurídicamente relevantes de la disputa y muchos tenían problemas al tratar de entender el objetivo del juicio (los jueces y los abogados normalmente se quejaban de que no era claro los que las personas sin representación estaban solicitando cuando comenzaba el caso o presentaban solicitudes)". Véase MOORHEAD (2007) pp. 405-424 (la traducción es propia).

${ }^{41}$ Moorhead (2007). La semejanza del caso chileno con otras realidades se mantiene. "Más aún, la complejidad y la incapacidad de los tribunales de trabajar de una forma que fuera comprensible para los litigantes suponía una parte importante del problema”. (la traducción es propia).
} 
identificar los medios de prueba que se encuentran disponibles. En este sentido la jueza indicó que esto requiere que ella realice una serie de averiguaciones consultándole a la parte acerca de quién podría saber de estos hechos, si existen testigos potenciales y así sucesivamente. Según la Jueza 3 las acciones que ella debe llevar a cabo son muy similares a las que un abogado realiza con su cliente en su oficina, siendo la principal diferencia que el abogado previo a la presentación de la demanda ha tenido el tiempo y oportunidad suficiente para estudiar el caso, mientras que ellos deben hacerlo en condiciones inferiores.

Como se mencionó, esta intervención también implica problemas éticos para los jueces. Nuevamente la Jueza 3 es clara al identificar que el rol dual juez-abogado es difícil de manejar, especialmente porque supone que eventualmente está ayudando a una de las partes de la contienda.

La Jueza 5 argumenta a este respecto que existe una diferencia importante entre las medidas de protección y los casos de violencia intrafamiliar. Sostiene que cuando se trata de casos de medidas de protección, dado que el juez de familia tiene el rol de protector del interés superior del niño, ella tiene mayores atribuciones para actuar de una forma más inquisitiva $^{42}$. Este no sería el caso en las causas VIF, en estos últimos los jueces actúan sin soporte legal y bajo su propia conciencia, debiendo escoger entre limitar su ayuda a la parte en solo aquello que la ley expresamente la autoriza o ir más allá de esta y actuar asistiéndola en gran medida.

Lidiar con partes sin abogado constituye un procedimiento intrincado para los jueces de familia, dado que estos se ven forzados según las necesidades de la justicia a abandonar su postura imparcial y enfrentarse con partes que se encuentran confundidas y perdidas. Se trata de un procedimiento en que los jueces refieren no estar cómodos y con el cual deben bregar en cada oportunidad.

42 Moorhead (2007) p. 412. Se observa que las dudas enfrentadas por los jueces de familia chilenos con relación a qué tan inquisitivo debe ser su comportamiento son también experimentadas por jueces de Inglaterra y Gales.

"Una preocupación particular de los jueces era asegurar que formas de interrogación que eran inapropiadas fueran impedidas, pero algunos jueces sugirieron que ellos participaban en la formulación de las preguntas:

[Litigantes en persona] simplemente no entienden el concepto de contraexamen, entonces tú terminas diciéndoles a ellos: no le corresponde a usted decirme de qué se trata su caso, pero puede haber algunas preguntas que usted desea hacerle a la contraria que si usted me las dice entonces yo puedo ayudarle a formular dichas preguntas.

Pero otro juez indicó que él ayudaría al litigante a determinar sus preguntas pero que él mismo no interrogaría al testigo:

Uno tiene un deber con ambas partes y conducir un contraexamen sustituyendo a un litigante sin abogado supone primero que uno tiene que saber el caso con algún nivel de detalle. Y no es la función del juez, la función del juez es decidir, no contrainterrogar a los testigos de la otra parte”. (La traducción es propia). Con todo, la cita permite igualmente notar algunas diferencias entre lo experimentado por el juez chileno y el inglés, en el sentido de que el segundo parece ser más cauteloso acerca de asumir un rol inquisitivo. Esto se desprende del hecho que ninguno de los jueces ingleses citados por el estudio de Moorhead, incluso aquel más dispuesto a intervenir, termina interrogando al testigo. Más bien el dilema está en si ayudar o no a la parte a formular sus preguntas, pero ningún de ellos indica que reemplazan a la parte al momento de interrogar al testigo, cuestión que los jueces chilenos sí hacen. Se observa entonces que lidiar con litigantes sin abogado obliga al juez a repensar su rol acercándolo a un rol más inquisitivo, no obstante, la cita da cuenta de que existe una alternativa intermedia entre no hacer nada y hacer todo, que parece ser aquella que los jueces ingleses asumen. 


\section{c) La voz perdida de los niños}

Uno de los principales roles que la ley asigna al juez de familia es el de garantizar y velar por los derechos de los niños, niñas y adolescentes. En términos prácticos este rol obliga al juez a considerar la opinión del niño cuando este se encuentra involucrado en el caso y la decisión que tomará pueda afectar sus derechos. En este contexto uno de los derechos más importantes de los niños es el derecho a ser oído. Este derecho implica que según las características del niño involucrado, su edad por ejemplo, el juez debe determinar si para resolver el asunto controvertido debe escuchar su parecer ${ }^{43}$.

En la práctica de los tribunales de familia la forma en como este derecho se protege es mediante la creación de la audiencia reservada, en la cual el juez de familia solo o acompañado por el consejero técnico se reúne con el niño e interactúa con él.

Según las entrevistas sostenidas con los jueces de familia, esta particular actividad supone para muchos de ellos una serie de problemas y desafíos. Posiblemente el ejemplo más claro de estas dificultades pueden verse en la opinión vertida por la Jueza 3, quien se desempeña como jueza de familia en la Región del Maule desde el año 2006, teniendo más de 7 años de experiencia en esta judicatura. Al respecto esta sostiene: "Entrevistar a los niños es un desafío. Tú no sabes cómo entrevistarlos y cómo interpretar la información que ellos proveen... Me preocupa las posibles consecuencias que esta actividad pueda tener en el futuro del niño".

De la lectura de la opinión emitida por la Jueza 3 es posible observar que sus preocupaciones no se refieren a dudas sofisticadas sobre qué tipo de preguntas deben realizarse o cómo escoger entre diversa técnicas y cuál es la mejor. Por el contrario, las preocupaciones que aquejan a la Jueza 3 dan cuenta de dudas elementales, como no saber de qué forma actuar, cómo acercarse al niño, qué preguntar y cómo evaluar la información provista por este. En este sentido la jueza es dejada solo a sus instintos sobre cómo manejar la situación.

Una opinión similar manifiesta el Juez 2. Este juez se ha desempeñado como juez de familia desde el 2006 y desde el 2009 ha trabajado en los tribunales de familia de la Región Metropolitana. Al respecto, sostiene que para él una de las actividades más difíciles de manejar como juez de familia es la entrevista reservada, manifestando que nadie está realmente preparado para realizar la entrevista y que para él la parte más compleja es el manejo emocional que se requiere, cuestión fundamental para el éxito de la actividad.

Es importante mencionar que no todos los jueces entrevistados calificaron la entrevista reservada como un problema, con todo de sus relatos se desprende que en la práctica enfrentaban duda similares a las de los jueces 2 y 3 .

En el caso de la Jueza 7, quien es juez de familia desde el 2006 en los tribunales de la Región del Maule, cuando se le preguntó acerca de su experiencia respecto de la entrevista reservada sostuvo que al principio era un problema para ella, pero hoy estima que ya no es así. Explica que a esta altura ya ha desarrollado una serie de prácticas al momento de llevar a cabo la actividad, las cuales cree le permiten evitar las consecuencias nocivas a las que la Jueza 3 aludía. La Jueza 7 indica que ella trata de crear un ambiente lúdico para el niño, en el cual una simple conversación se lleva a cabo, olvidándose del contexto adversarial que el

43 Correa y Vargas (2011) pp. 179-187. 
juicio supone. Respecto de estas técnicas la Jueza 7 reconoce que todas ellas han sido producto de su inventiva, ya que nadie se las enseñó.

Es interesante notar la diferencia de perspectiva de las juezas 3 y 7 . En términos prácticos ambas actúan según su criterio e instintos, ya que ninguna ha tenido entrenamiento en la materia, la única diferencia parece ser qué tan preocupadas se muestran respecto de las consecuencias de sus acciones en el niño que están entrevistando.

Con relación a los jueces 4 y 6, de la Región del Biobío y Maule respectivamente, ambos sostienen que no tienen problemas lidiando con la entrevista personal, ya que cada vez que lo requieren son asistidos por un consejero técnico. Ambos jueces sostienen que son estos profesionales los que les asisten en cómo proceder respecto de la entrevista y cómo evaluar la información que el niño ha provisto. En el caso de la Jueza 6, quien primero trabajó en los tribunales de menores y posteriormente asumió como juez de familia el 2005, ella reconoce que si no fuera por la participación del consejero y estuviese sola con el niño, sería para ella un verdadero problema enfrentar la situación, siendo difícil de manejar.

Las entrevistas muestran que no todos los jueces de familia trabajan con el consejero técnico en el caso de la entrevista reservada. La información recopilada da cuenta de dos razones para ello.

En el caso de los jueces 4 y 5, ambos de la Región del Biobío, estos manifiestan que son "suertudos", ya que en su tribunal el nivel de los profesionales que trabajan en el consejo técnico es muy alto, encontrándose siempre estos disponibles para asistirlos. Al respecto, cuando el Juez 4 fue entrevistado, este sostuvo que esta actividad nunca era un problema porque había un número suficiente de consejeros, psicólogos, disponibles.

El segundo factor que determina si los jueces trabajan con los consejeros es el nivel de confianza que los primeros tengan en los segundos. En el caso de la Jueza 3, por ejemplo, ella indicó que el trabajo del consejero en su tribunal no era de ninguna ayuda lidiando con esta tarea en particular.

En conclusión, la información recopilada mediante las entrevistas da cuenta de las dificultades y dudas que los jueces entrevistados enfrentan cuando deben realizar la entrevista reservada, las cuales están vinculadas a la disponibilidad de un consejero técnico y la confianza que los jueces tengan en este. Los entrevistados sostienen que muchas veces enfrentan esta actividad solos, con muchas dudas y preocupaciones.

A diferencia de otros hallazgos de este estudio, el presente ha sido detectado en Chile ya el año 2011, en el trabajo de las profesoras Macarena Vargas y Paula Correa de la $\mathrm{UDP}^{44}$. Estas sostienen en sus conclusiones, después de haber revisado carpetas y escuchado audios de audiencia reservada, hallazgos similares a los que este documento identifica: "Otro elemento que caracteriza este mecanismo dice relación con la falta de claridad de los operadores sobre los objetivos de la audiencia reservada. A juzgar por los audios revisados, se pudo constatar distintas aproximaciones de los jueces para enfrentar esta audiencia. Algunos dan a esta actuación el formato de un interrogatorio más que de un diálogo, haciendo al niño preguntas cerradas y abiertamente sugestivas (...) En efecto, en algunos casos de cuidado personal se observó que en la audiencia reservada se insta a los niños a evaluar las

44 Correa y Vargas (2011). 
habilidades parentales de quienes los rodean más que a expresar sus deseos y sentimientos, sin el resguardo psicológico necesario(...) Otros utilizan esta actuación como si se tratara de una sesión de orientación o consejería, informando a los niños acerca de lo que sucederá en el proceso, aconsejándolos sobre cómo comportarse en el futuro o sobre cómo llevar adelante la relación con sus padres o adultos significativos. Los niños dejan de ser entrevistados y pasan a ser receptores del mensaje del juez, que en su calidad de autoridad los orienta (o incluso los reta) respecto de la relación con su padre, madre o familia. Por lo general, a través de ese mensaje se busca que el niño modifique en algo las preferencias o intereses manifestados durante la entrevista (...) Por otra parte, cabe señalar que si bien la ley de tribunales de familia contempla la participación de los consejeros técnicos en estas actuaciones, de acuerdo a la información recogida en los audios y carpetas ellos tienen un papel secundario. Habitualmente, no formulan preguntas en forma directa o solo lo hacen a requerimiento del juez y al final de esta actuación” 45 .

\section{d) El exceso de confianza de los jueces}

La expertise del juez de familia para dirigir audiencias es algo que los jueces y abogados entrevistados acuerdan como fundamental. Esto se debe a que la justicia de familia funciona primordialmente a través de audiencias, las cuales son conducidas por los jueces. En esta sección se explican las diferentes perspectivas que los entrevistados tienen sobre la materia.

Respecto de la postura de los jueces de familia con relación a su desempeño en audiencias, la mayoría de los entrevistados opinaron que ya poseían una vasta experiencia en la materia. En este sentido dado que todos tenían más de cinco años en el puesto, estos pensaban que las dinámicas de las audiencias y su dirección no constituían un misterio o un tema para ellos. De hecho se mostraban muy confiados en sus capacidades.

Esta confianza disminuía cuando se les consultaba por la experticia de sus colegas. Ante este tipo de preguntas los jueces reconocían que algunos de sus pares tenían efectivamente problemas pero nada crítico, solo reconociendo que algunos de estos necesitaban tener una mejor comunicación con las partes mismas y tener un mejor entendimiento de la relevancia de esta actividad ${ }^{46}$.

El contraste con la opinión de los abogados de familia es notorio respecto de este punto. Estos últimos advierten que los jueces presentan una serie de problemas respecto de la dirección de audiencias.

45 Correa y Vargas (2011) pp. 188-190. La correlación entre los resultados del presente artículo y el de las profesoras Vargas y Correa parece ser alta. Primero, el hecho de que los jueces tienen diversas aproximaciones a la audiencia reservada según da cuenta dicho estudio, aparece como la contracara de que los jueces tienen una aproximación intuitiva hacia esta entrevista, cuestión que los jueces 2 y 3 de este artículo manifiestan claramente. Lo mismo puede decirse del rol de los consejeros técnicos en esta actividad, en donde el estudio de Vargas y Correa da cuenta de un rol secundario en muchas ocasiones. Esto tiene sentido según lo identificado en esta publicación, en la medida que todo se traduce en la confianza que el juez tenga en las habilidades del consejero.

46 La mayoría de los jueces entrevistados tenían la opinión de que era importante que cada juez fuera un buen anfitrión no solo con los abogados, sino que también con las partes. En este sentido una de las particularidades de la justicia de familia es que el procedimiento exige que las partes estén presentes en las audiencias, situación que no se da en otro tipo de materias, en donde los jueces solo se relacionan con los abogados. 
En primer lugar, los abogados de familia manifiestan que existen importantes diferencias entre aquellos jueces de familia que fueron entrenados durante el nuevo sistema y aquellos que provenían de los antiguos tribunales de menores. Estos últimos son aquellos que los abogados identifican como los que más problemas presentan al momento de dirigir las audiencias.

Una caracterización de estas dificultades es presentada por la Abogada 1, de la Región Metropolitana. La Abogada 1 tiene más de ocho años de experiencia como abogada de familia. Asimismo, ha hecho grandes esfuerzos para obtener una formación adecuada que le permitiera especializarse en el área, de hecho posee un magíster en derecho de familia y un diplomado en la misma área.

La Abogada 1 señala que los jueces de familia que provienen del sistema antiguo, en general, enfrentan enormes problemas en el contexto de las audiencias, al momento de resolver objeciones, al interactuar con los abogados, dirigir el debate y afirma finalmente que muchos de estos jueces derechamente no entienden las dinámicas del nuevo sistema ${ }^{47}$.

Curiosamente la misma situación es corroborada por uno de los jueces entrevistados, el Juez 4, quien sostiene que aquellas veces que ha debido escuchar audios de sus colegas le ha permitido oír las dificultades que estos enfrentan en las audiencias: "Muchas veces cuando mis colegas tienen que decidir respecto de un incidente estos no son claros, se toman mucho tiempo. Hacen recesos, pero se sabe que van a consultar o tratar de redactar algo más o menos estructurado (...) se trata de saber qué hacer, si se puede plantear, si corresponde resolver. Ante una objeción qué hacemos, les vamos a dar traslado (...) Se trata de manejar bien el trance para salir de situaciones para las cuales uno no está preparado. La audiencia tiene que irse dando de forma natural y uno tiene que estar en condiciones de llevarla adelante en una forma ordenada, que se entienda, que sea coherente".

La experiencia de los abogados de familia litigando casos frente a jueces formados bajo el nuevo sistema es mejor, de hecho están de acuerdo en que estos últimos tienen una comprensión superior de las dinámicas del nuevo sistema. Con todo, los abogados igualmente identifican problemas en la dirección de las audiencias, especialmente el desarrollo de prácticas problemáticas.

La primera de estas prácticas se refiere al hábito de muchos jueces de intervenir en el trabajo de los abogados durante la presentación de la prueba. Como se sabe la ley de tribunales de familia establece que son las partes las responsables de presentar los medios de prueba y conducir el interrogatorio de los testigos. Excepcionalmente la ley permite al juez interrogar al testigo, pero solo preguntas destinadas a aclarar o adicionar algunos aspectos que surgieron durante el interrogatorio de las partes. Según los abogados de familia entrevistados, existe un hábito en los jueces de ir más allá de la letra de la ley y en muchos casos los jueces toman un rol activo en el interrogatorio y contrainterrogatorio de los testigos.

\footnotetext{
47 Su opinión es apoyada por el abogado 4, quien ejerce exclusivamente en materia de familia en la Región del Biobío y por el abogado 5 quien ejerce en la Región Metropolitana. A mayor abundamiento, el abogado 5 indica al referir se a los jueces provenientes del sistema de tribunales de menores que: "contra ellos es difícil argumentar una idea que ellos no tienen (...) decirles que yo voy a organizar el orden en que presento mi prueba es insultar al juez, parece no cachar [sic] que la presentación de la prueba es estratégica. Es algo que parece no estar claro".
} 
Para los abogados este tipo de comportamiento es problemático ya que implica una decisión del juez de ayudar a la parte cuyo abogado no está preparado para enfrentar el caso o derechamente está haciendo un mal trabajo. Como consecuencia de esta práctica se genera en los abogados de la contraparte una sensación de injusticia y frustración, al ver como su preparación se va al tacho de la basura. La situación empeora cuando los jueces que dicen interrogar lo hacen utilizando una técnica deficiente, mediante el abuso de preguntas sugestivas las cuales disminuyen la calidad de la información que proviene del testigo ${ }^{48}$.

La segunda práctica identificada está vinculada con la anterior y se refiere al hábito de los jueces de familia de establecer límites de tiempo muy estrictos para el ejercicio del interrogatorio y contrainterrogatorio. Según el Abogado 1 algunos jueces hoy siguen estableciendo límites de 5 minutos para el desarrollo de este tipo de ejercicios, cuestión que según el abogado vuelve el desarrollo de la actividad inútil.

Ambas prácticas son reconocidas por los jueces entrevistados, pero la mayoría no parece ver un problema en ellas, argumentando que estas responden a ideales de justicia y manejo eficiente del tiempo del tribunal.

Con relación a los límites temporales, los jueces argumentan que estos responden al mal trabajo desarrollado por los abogados al momento de conducir sus interrogatorios. En este sentido las restricciones de tiempo usualmente siguen a abogados que no están preguntando aquello que deberían o que derechamente están yendo de pesca, preguntando solo por si encuentran algo.

Se observa entonces una falta de confianza por parte de los jueces de familia respecto del trabajo de los abogados particulares en el área de familia. Con todo, también se observa una confianza excesiva por parte de los jueces de familia en sus propias capacidades en materia litigación.

$\mathrm{Al}$ respecto, la mayoría de los jueces entrevistados reconocen que no recibieron entrenamiento en litigación o respecto de nociones como teoría del caso, la diferencia entre

\footnotetext{
48 El mismo fenómeno se ha detectado y descrito en el ámbito de la justicia laboral. Al respecto existe un fallo pronunciado por la Corte de Apelaciones de Antofagasta que se hace cargo del problema, especialmente desde la perspectiva de la posibilidad del litigante de objetar las preguntas realizadas por el juez. Así la Corte indica: "Resulta necesario indicar, no obstante su evidencia, que ciertamente el tribunal, en la práctica, puede vulnerar las formas legítimas de interrogación señaladas en la ley, pues podría interrogar sobre hechos que no son materia de la controversia, efectuar preguntar asertivas y, todavía más, contener elementos de juicio que condicionen la respuesta. Conclusión pacífica debiera ser que ello no resulta procedente pues (...) si se analiza la ratio de la prohibición, como se adelantó, controlar la calidad de la información que ingresa al juicio, deviene que esta aún más debe regir para el tribunal, en la medida que puede afirmarse que, especialmente ciertos testigos de bajo nivel intelectual o escaso nivel cultural, pudieran ser proclives a responder positivamente las afirmaciones que efectúa el juez". Palomo y Matamala (2011). La cita en cuestión parece ser particularmente consistente con lo ocurrido en familia y lo aseverado por la Jueza 2 al momento de examinar la situación de las personas que concurren sin abogados, cuando esta indicó que general se trata de "personas privadas socio-culturalmente". Otro aspecto relevante de este fallo se refiere a que la ratio de la prohibición estaría en controlar la calidad de la información. Es importante notar que esta "calidad de la información" no solo puede verse afectada cuando el juez realiza preguntas de una manera prohibida por la ley, sino que ese mismo peligro surge también cuando el juez pregunta en extenso y no tienen idea alguna de lo que el testigo sabe o no sabe. Esto se percibió en la cita 42, cuando el juez inglés indicó que para poder interrogar testigos "uno tiene que saber el caso con algún nivel de detalle". ¿Cómo puede controlarse la calidad de la información que provee un testigo si no se tiene claro que es lo que sabe y lo que no?
} 
el examen directo y el contraexamen, entre otros. Asimismo, ninguno de los entrevistados tiene experiencia previa al asumir su puesto como abogado litigante. Con todo, estas carencias no son consideradas relevantes por los jueces y muchos de ellos creen firmemente que se encuentran en mejor posición que los abogados mismos para determinar qué preguntas hacer al testigo, incluso si es la primera vez que se reúnen con el testigo y recién están conociendo el caso. En este contexto, surge la pregunta de hasta qué punto el juez de familia puede hacer un mejor trabajo que el abogado al momento de interrogar un testigo si no tiene mayor claridad acerca de lo qué el testigo sabe, noción elemental de litigación.

$\mathrm{Al}$ respecto el Abogado 4 presenta una reflexión que parece resumir el estado actual de esta problemática: "El problema es que a los jueces de familia no se les ha enseñado litigación desde la perspectiva del litigante, ellos no entienden las consecuencias que de sus decisiones y muchas veces ellos no entienden cuál es el objetivo del litigante. No existe un lenguaje común entre juez y abogado”.

Es importante resaltar la última frase pronunciada por el Abogado 4, que refiere que no hay un lenguaje común entre abogado y juez. Es posible que la falta de experiencia de los jueces en temáticas de litigación, así como la falta de experiencia en representar a clientes y lo que ello involucra, contribuya a esta falta de lenguaje común. Es, por tanto, poco sorprendente que para la mayoría de los jueces de familia sea difícil abstenerse de interrogar a los testigos, pasando a llevar el trabajo del abogado y su rol en el sistema procesal de familia. En este sentido pareciera que la inexperiencia en el rol de litigante hace que el juez no entienda qué tanto daño produce en los esfuerzos del abogado y en su estrategia al momento de interrumpirlo y no permitirle desarrollar su trabajo.

Asimismo, parece ocurrir un segundo fenómeno, una especie de retroalimentación negativa entre ambos actores. En la medida que el juez por motivos de agenda y baja calidad de la representación desarrolla la práctica de interrumpir a los abogados, a veces sustituyéndolos en los interrogatorios, se generan bajos incentivos para los abogados de hacer bien su trabajo, ya que saben que es el mismo juez quien finalmente terminará haciéndolo. A su vez, el abogado poco preparado forzará al juez en cada audiencia para que este actúe y perpetúe la práctica. Se da la paradoja que son los mismas prácticas de los jueces, aquellas destinadas a resolver problemas de baja calidad en la representación, las que terminan permitiendo la existencia de espacios en que abogados poco preparados puedan actuar en juicio sin sufrir las consecuencias de su falta de profesionalismo.

En conclusión los jueces no confían en los abogados, curiosamente siendo estos quienes deben presentar el caso y llevar la prueba. La mochila del juez se hace cada vez más pesada.

\section{REFLEXIONES ACERCA DE LA INFORMACIÓN OBTENIDA}

Ciertamente los problemas detectados no son los únicos que enfrentan los jueces de familia. En este sentido para algunos representa un problema lidiar con las falencias de la red social. Con todo, esto parece ser un problema que no depende de los jueces mismos. Para otros jueces es igualmente un problema lidiar con las presiones y plazos que las diversas actas administrativas imponen en ellos, obligándolos a "correr" con el fin de cumplir con las metas. No obstante, para otros jueces la llegada de las actas y sus exigencias es visto 
como algo positivo, ya que uniforman cargas de trabajo y permiten el mejoramiento de la justicia de familia, tal como estiman los jueces 3 y 4 .

Ahora bien, los problemas detectados y desarrollados en este texto son aquellos respecto de los cuales existe unanimidad entre los entrevistados o que se reflejaron en la mayoría de las entrevistas. ¿Qué puede decirse de estos problemas? Es posible realizar dos lecturas de aquellos.

\section{a) Primera lectura: CONOCIMIENTO PRÁCTICO VS CONOCIMIENTO JURÍDICO}

Las experiencias relatadas tanto por los jueces de familia como por los abogados particulares han permitido determinar que los primeros al momento de realizar una serie de actividades enfrentan dificultades. Así se ha identificado que los jueces de familia tienen diversos problemas al momento de dirigir audiencias, cuando se trata de conducir y valorar la entrevista reservada con niños, niñas y adolescentes, al interactuar con partes sin representación y en la dinámica relacional que sostienen con los abogados litigantes privados.

En primer lugar, las carencias o problemas detectados no parecen ser de una importancia menor. Es decir, no solo se trata de actividades que los jueces realizan regularmente, sino que son actividades centrales para el cumplimiento de las diversas funciones y roles que estos están llamados a desarrollar en el contexto del sistema procesal establecido por la ley 19.968.

En este sentido, una adecuada comprensión y ejecución de la entrevista reservada con el niño, niña o adolescente parece ser una herramienta fundamental para el rol que el juez cumple como garante del interés superior de niño, dado que es esta la oportunidad procesal para que el juez pueda escuchar al niño, puede determinar su voluntad y pueda valorarla en función de su desarrollo progresivo.

Asimismo, el saber lidiar con partes sin representación letrada resulta ser una cuestión fundamental para el cumplimiento del rol judicial cuando es la misma ley de tribunales de familia la cual por consideraciones de efectiva intervención del sistema judicial establece que en materias de VIF o de medidas de protección no es necesario actuar con abogado. Esto supone que si la parte normalmente no accede con abogado y el juez no lo entiende cabalmente, entonces la persona se encuentra en un escenario muy complejo, en el cual su acceso a la justicia es de baja calidad.

Igualmente, se supone que uno de los principales cambios que introdujo la ley de tribunales de familia fue la creación de un sistema que funciona mediante audiencias, las cuales operan como un mecanismo que al momento de tomar las decisiones más importantes asegura que estas puedan darse en un escenario de respeto al debido proceso y que la decisión que se está tomando será basada en información de la mejor calidad posible. Es por tanto vital que los jueces, para cumplir con su rol, puedan desempeñarse adecuadamente en las audiencias, comprendan a cabalidad su rol y el rol que las partes les corresponde según los objetivos establecidos por el legislador. La información recopilada no solo da cuenta de que existen jueces que presentan deficiencias básicas respecto de la dirección de audiencias, sino que también el desarrollo de prácticas problemáticas como la excesiva intervención de los jueces en el interrogatorio de los testigos y el desarrollo de prácticas de "subvención" que afectan el rol que los abogados están llamados a cumplir en un sistema como aquel 
establecido en la justicia de familia, el cual confía en una lógica adversarial para producir la mejor información posible.

En segundo lugar, es interesante notar qué tipo de dificultades son las que enfrentan los jueces. Se observa así que las carencias y limitaciones presentadas consisten en no saber cómo actuar, qué preguntar, qué hacer, entre otros. También no debe olvidarse que los obstáculos enfrentados tienen una dimensión ética, como por ejemplo aquella que surge cuando el juez debe decidir si interviene o no en la labor de rendición de prueba de una parte cuando está claramente no está haciendo un buen trabajo, con el subsecuente riesgo de perder su apariencia de imparcialidad.

Ambas dimensiones permiten concluir que las dificultades identificadas se refieren a carencias vinculadas a la falta de destrezas y competencias (saberes prácticos) y no a la ausencia de conocimientos jurídicos. De hecho ninguno de los jueces y abogados entrevistados indicaron que el principal problema de los jueces era desconocer legislación fundamental o doctrina esencial de la materia.

Es por tanto posible entender o leer los problemas detectados bajo el prisma de la capacitación de los operadores del sistema de justicia de familia. Así, los problemas que los relatos dan cuenta pueden derivar de una ausencia de una adecuada capacitación, ya sea porque esta no presenta una oferta destinada específicamente a paliar los problemas detectados dado que estos pueden no haber sido identificados o porque algunos o todos ellos sí han sido identificados pero la metodología implementada es inadecuada para lograr el traspaso de saberes prácticos en oposición a saberes jurídicos. Se vuelve por tanto necesario indagar acerca de la oferta de formación y perfeccionamiento, especialmente respecto de los jueces de familia, investigación que deberá ser emprendida en el futuro a efectos de complementar el análisis desarrollado en el presente documento, pero que actualmente va más allá del objetivo planteado en la introducción.

\section{b) Segunda lectura: la PeRCEPCión del PRESTigio y SUS CONSECUENCIAS}

Una lectura un poco más sofisticada permite identificar un tema mayor, respecto del cual los problemas previamente identificados son solo un síntoma. Este se encontraría de alguna forma escondido en las entrevistas y puede proveer una explicación a estos y a otros problemas detectados que afectan a la justicia de familia. Se trata del prestigio que la justicia de familia tiene en la comunidad legal chilena y sus consecuencias.

Como se mencionó previamente, uno de los problemas detectados se refiere a cómo el trabajo de los jueces es afectado por el desempeño de los abogados particulares. Como se explicó muchos jueces se quejan de que los abogados privados llegan a las audiencias en malas condiciones, claramente a improvisar. Este hecho motiva una pregunta: ¿Qué explica que abogados que están cobrando honorarios, se atrevan a asistir a audiencias sin preparación de su caso o sin saber qué hacer? El fenómeno captó la atención de todos los entrevistados y los jueces comparaban con la justicia penal, en donde opinaban que no esto no ocurría, entonces ¿por qué esto ocurre en la justicia de familia?

Para algunos jueces, los jueces 4 y 6 , esto se debe a que la mala reputación de los tribunales de menores se traspasó al nuevo sistema. En este sentido los abogados que litigaban en menores miraban en menos el área dado que usualmente involucraba bajos montos 
en dinero que no justificaban un gran esfuerzo y dedicación, lo que siempre colocaba a la justicia de familia en un peldaño inferior. Otros jueces piensan que los abogados problemáticos son aquellos que vienen del antiguo sistema, quienes no se han adaptado a las exigencias del nuevo.

Los abogados entrevistados identificaron el mismo problema y una potencial explicación es posible de observar en las palabras del Abogado 4. Para este abogado el factor que explica la actitud de algunos de sus colegas está en que estos no entienden la real complejidad que existe en la justicia de familia, especialmente en materia de conocimientos y habilidades. El Abogado 4 indica que la justicia de familia no solo implica entender el derecho aplicable, sino que dominar habilidades de litigación y una serie de habilidades blandas, incluidas una fortaleza emocional. Cree que la mayoría de sus colegas piensan que litigar causas de familia es simple y por ello piensan que no es necesario tomárselo en serio. Finaliza su intervención indicando que "familia es el área olvidada del derecho. Nadie la toma en serio, ni la mayoría de los jueces, ni los abogados".

Se vuelve interesante reflexionar sobre el porqué los abogados no toman en serio el área de familia. La clave para responder esta pregunta puede observarse en una cita de la Jueza 1 durante la entrevista conducida. Esta jueza piensa que las Cortes Superiores tienen una opinión peyorativa de la justicia de familia y los jueces de familia, ya que muchos de los jueces superiores se refieren a esta área del derecho como una especie de trabajo social, como algo distinto al derecho. Una idea similar fue posible de observar cuando uno de los abogados entrevistados indicó que la justicia de familia "no es derecho", generándose la paradoja de que incluso un abogado que se dedica casi exclusivamente al área de familia termina reforzando el prejuicio existente.

Una posible explicación de todo esto está en las particularidades de la justicia de familia y el derecho de familia. En este sentido la experiencia chilena muestra que en el contexto de un conflicto jurídico familiar el componente legal del debate es menor y usualmente no es la parte preeminente de la discusión ${ }^{49}$, sino que la dimensión emocional e interdisciplinaria del conflicto tiene mucha más relevancia para la resolución del caso ${ }^{50}$.

\footnotetext{
${ }_{49}$ Muy gráficas al respecto son las palabras pronunciadas por el ex presidente de la Corte Suprema de Chile, Sr. Ministro Rubén Ballesteros, cuando en un discurso de inauguración del Juzgado de Familia de Talca en agosto de 2012 indicó: "En efecto, los conflictos que resuelven los Tribunales de Familia no son solo jurídicos. En ellos hay involucrada una fuerte tensión emocional, derivada principalmente de las desavenencias y rupturas conyugales y de pareja". BALLESTEROS (2012).

${ }^{50}$ Esta parece ser una característica general de la justicia de familia que excede de la realidad chilena. Por ejemplo Penny Darbyshire al examinar la justicia de familia en Inglaterra y Gales señala: "Estas son mis observaciones, no tomadas de la literatura. Primero, cuando una familia se ha roto, las emociones están siempre recargadas. (...) Tercero, discusiones jurídicas surgen inusualmente. De hecho nunca escuché mencionar la ley en todo el tiempo que estuve en los tribunales de familia (...) Cuarto, el rol del juez aparece como distinto. El juez no va a decretar el divorcio en algunos casos a menos que esté satisfecho que un acuerdo justo ha sido alcanzado(...) el trabajo del juez consiste en disipar la confrontación natural que ha surgido entre las partes que esta vinculadas en el caso. Con este fin el juez no puede ser pasivo. Algunos describen su rol como inquisitivo (...) Algunos manipulan los procedimientos para llegar al resultado deseado (...) están listos para asumir un rol informal de mediador (...)". DARBYShiRe (2011) pp. 262-263 (la traducción es propia).

Para el caso de los Juzgados de Familia de Argentina resulta ilustrativo el trabajo de Beatriz Kohen, quien en lo pertinente señala: "De hecho, la contribución más importante que las [juezas] mujeres parecen aportar a la
} 
Es posible pensar que en una comunidad jurídica como la chilena, en donde buena parte del entrenamiento de los abogados es muy tradicional, focalizándose en el estudio del derecho y no mucho más ${ }^{51}$, la percepción de una preeminencia en la discusión de factores no jurídicos sea considerada como algo negativo o de poca sofisticación. Así uno de los abogados entrevistados calificó la materia de familia como "simple". Al ser consultado de por qué indicaba esto señaló: "la simpleza está en todas las leyes que regulan la materia de familia; ley de procedimiento de familia tiene 100 artículos bien sencillos, parece ser un resumen del código procesal penal, ley de divorcio se ocupan 3 artículos, alimentos tiene 10 artículos, violencia intrafamiliar también es breve" 52 .

Por un lado, sería del caso que el abogado que goza de una formación tradicional no percibiría la real complejidad detrás de los casos de familia al razonar, más o menos, de la siguiente forma: a menor cantidad de normas, menor complejidad jurídica, por tanto menor destreza necesaria para resolver conflicto. Por otro, la preeminencia de un componente emocional y de una perspectiva interdisciplinaria propia del área, contribuirían a la menor preeminencia del debate jurídico, lo que provocaría que la justicia de familia fuese finalmente percibida como más cercana al trabajo social que al derecho ${ }^{53}$. Sería de ahí de donde surge el bajo prestigio del área ${ }^{54}$.

justicia de familia consiste en la introducción de un enfoque interdisciplinario en la resolución de los problemas familiares" (traducción del autor). Véase KoHen (2008) p. 116. Finalmente el mismo rasgo se destaca en el sistema español Escuela Judicial de España (2012).

Las citas dan cuenta de dos caras de la moneda. Una cara dice relación con el componente emocional de los conflictos de familia, rasgo que permea todo el debate dado los participantes y la naturaleza del conflicto. La contracara de esto es que resulta obvio que para lidiar con este tipo de conflictos no es suficiente una perspectiva netamente jurídica, sino que otros enfoques (perspectiva interdisciplinaria da cuenta Kohen) y métodos (soluciones colaborativas da cuenta Darbyshire) son necesarios.

51 GonZÁlez (2003) p. 15 y Baraona (2010) pp. 443-445.

52 En un sentido similar, aunque no se trata de información obtenida en una entrevista para el presente estudio, se encuentran las opiniones vertidas en el contexto de una conversación informal por un Ministro de Corte de Apelaciones (el cual no será identificado). Al discutir sobre la existencia de diverso prestigio entre jueces de primera instancia, este contestó afirmativamente usando dos ejemplos. Primero sostuvo que los jueces de tribunal oral en lo penal se creían superiores al resto dado que eran "los únicos que funcionaban de forma colegiada”. El segundo ejemplo que usó se refiere a los jueces de familia y los jueces civiles. Indicando que los primeros "a penas se saben dos leyes" mientras que los segundos son jueces de "cuello y corbata".

53 La existencia de áreas de la judicatura que gozan de diverso prestigio en una comunidad legal no es algo inusual. Por ejemplo Kohen sostiene que en la Argentina el prestigio de una u otra área de la judicatura está dado en buena medida por dos factores: la cuantía de los casos usualmente involucrados y el impacto político que normalmente conllevan. KOHEN (2008) p. 115.

Sobre el rol del prestigio en los abogados, no los jueces, véase como ejemplo KRITZER (2004) pp. 219-223.

54 Existe una teoría complementaria que también explica (parcialmente) el bajo prestigio de la justicia de familia. Esta explicación se basa en la perspectiva de género, existiendo en nuestra comunidad legal una asociación de lo masculino (positivo) y lo femenino (negativo) vinculada a la justicia de familia. Así la justicia de familia sería propio de las "mujeres", al tratarse de conflictos "emocionales" que exigen una perspectiva interdisciplinaria, mientras que otras áreas del derecho serían propiamente masculinas, al ser objetivas, dado que lo emocional no es parte del conflicto, y altamente sofisticadas, en oposición a poco legalistas.

María José Azócar ha explorado en detalle esta vertiente de la justicia de familia, específicamente el impacto que tuvo la perspectiva de género en el proceso de implementación de la reforma procesal penal y la reforma de los tribunales de familia. Azócar (2014). 
El prestigio de la justicia de familia, entendido como un área del derecho poco legalista, es algo que también afecta a los jueces de familia. Así es posible recordar las quejas constantes de los abogados a los tratamientos dados por los jueces de familia y su conducta abusiva, en donde la ley para muchos no parecía ser un límite en su actuar.

El comportamiento de los jueces refleja que para ellos la ley sustantiva y procesal parece cumplir un rol distinto de aquel que cumple para los otros jueces de otras áreas del derecho. Un ejemplo interesante fue proveído por el Juez 4. Cuando se le consultó acerca de por qué los abogados privados llegaban a las audiencias sin la adecuada preparación, este mencionó como explicación que muchos jueces se rehúsan a seguir lineamientos mínimos que orienten a dichos abogados, es decir, estos no saben realmente a qué van a las audiencias. El Juez 4 indicó que en diversas oportunidades ha hablado de esto con sus colegas, tratando de convencerlos, pero muchos de ellos lo acusaban de "seguir en exceso la letra de la ley". Las entrevistas dan cuenta de esta tendencia judicial, en la cual conceptos como debido proceso, el interés superior del niño y el principio de la desformalización significan todo y nada ${ }^{55}$, siendo usados para justificar una serie de decisiones que son caprichos del juez $^{56}$. En este sentido al menos, la ley tampoco es ley para los jueces de familia.

La mala imagen que los abogados tienen del trabajo de los jueces es algo que contribuye a disminuir el prestigio de la justicia de familia, en el sentido de que no solo es un área menos técnica, sino que es un escenario en que la ley no representa un límite para los jueces.

Finalmente existe cierta evidencia que indica que el bajo prestigio del área de familia impacta en quienes terminan siendo jueces de familia. En primer lugar, la mayoría de los jueces entrevistados reconocieron que ellos en un comienzo no querían ser jueces de familia, sino que del área penal, aunque hoy todos ellos reconocen que están muy satisfechos en esta área del derecho. Con todo, la predilección por otras áreas sigue vigente, especialmente para efectos de ascensos en el Poder Judicial.

Uno de los jueces entrevistados, la Jueza 1, manifestó que la mayoría de los jueces de su tribunal no eran muy buenos. Consultada por las razones de esta situación, manifestó que al interior de la Academia Judicial existía una visión de que los mejores candidatos deberían ir al área penal y no a justicia de familia. Fue en ese momento en que ella manifestó que la justicia de familia era percibida por los tribunales superiores como trabajo social.

No existe declaración del Poder Judicial, ni de la academia que apoye los dichos de esta jueza, con todo, hay información indirecta que apoya sus dichos. Así, una revisión de la información publicada por el Poder Judicial de Chile da cuenta que desde el año 2011

\footnotetext{
55 Carretta (2013) pp. 199-203.

56 Con relación a la desformalización la tesis de Francesco Carretta, juez de familia y académico, es que buena parte de estas decisiones discrecionales derivan del atribuir la calidad de "principio" a la desformalización por parte de los jueces de familia. "En este contexto jurisprudencial, no se tiene claridad si en virtud de la desformalización se pueden pasar por alto aspectos rituales claramente establecidos en la ley (plazos, notificaciones, etc.); sí existe la posibilidad que los jueces efectúen interrogaciones a las partes en forma paralela a las audiencias, incluso antes de las mismas, sobre aspectos vinculados al objeto del litigio; que anulen actuaciones que estimen viciadas, contra la aplicación estricta de los presupuestos de la nulidad procesal; cuál es el valor de la preclusión en dichos procesos, etcétera”. CARRETA (2014) p. 491.
} 
al 2014, 14 jueces de primera instancia han sido designados Ministros de Corte de Apelaciones. De estos 14 jueces, o bien no han sido nunca jueces de familia o, ninguno de ellos ha pasado directamente desde el cargo de juez de familia a Ministro de Corte, y todos ellos han sido jueces civiles o del tribunal del juicio oral en lo penal ${ }^{57}$.

Un segundo antecedente en esta línea surgió en el contexto de otro trabajo investigativo realizado por las profesoras Paula Correa y Macarena Vargas, previamente citado en este artículo. En dicha investigación se entrevistaron diversos jueces, incluidos Ministros de Cortes Superiores. Uno de estos indicó la siguiente aseveración, cuando fue consultado acerca de los desafíos que el derecho del niño a ser oído tiene para los ministros de las Cortes de Apelaciones: "Porque aquí no estamos analizando la ley, si ese es el gran tema... un paréntesis, ¿por qué los jueces de familia son abogados? Ah perdón, ¿tienen que ser abogados? Simplemente porque el código lo dice no más, pero que necesidad tenemos de preparación para el tema, que tiene que ser abogado, yo no le veo ninguna. A mi gusto puede ser tan buen juez de familia un profesor, un psicólogo, un asistente social, y un abogado, porque no, pero no es que sea únicamente, ah es que no sabe derecho, no importa, le pongo un asesor, o sea, al revés, en vez de ponerle un consejero técnico, le pongo un asesor jurídico, porque ojo, pestaña y ceja, la cantidad de normas que maneja el juez de familia son ínfimas, unas poquitas de procedimiento que uno se las aprende rápidamente hasta le puedo hacer un manual y de manejo otras poquitas más, porque todas son como usted dice, el interés superior del niño, y qué ley es esa, y dónde está eso y dónde está definido eso, en ninguna parte, y todo es así, y para establecer un régimen de 3 a 5 o de 6 a 9, yo no veo que tanto derecho tiene uno que saber, y para establecer que el ñato gana 300 lucas cuanto le sacamos para que dé la pensión alimenticia, tampoco sé cuanto derecho hay que saber y eso más tienen que ver con la intuición la práctica, con la cachativa, digamos. Por ahí va, y eso no es privativo de los jueces, materias jurídicas propiamente tales son ínfimas, poquísimas, que manejan los jueces" (el destacado es propio) ${ }^{58}$.

El entendimiento de la justicia de familia como algo jurídicamente poco legalista o poco técnico influye en que muchos de los que operan en ella no se tomen en serio el área. En el caso de los abogados particulares esto impacta en la calidad de la representación y las audiencias. Los jueces, por un lado, deben subsidiar a dichos abogados generando la imagen de una justicia poco imparcial. Por otro, los jueces igualmente manejan una noción de la ley distinta a la de sus colegas, muchas veces manipulándola, reconociendo que en familia la ley opera distinto lo cual contribuye a su bajo prestigio, ya que familia no es derecho. El prestigio sigue decayendo. Ese mismo prestigio impacta en quienes se dedican a la justicia de familia. Algunos solo llegan a ella porque no pueden optar a la justicia penal, predilección que las mismas Cortes Superiores parecen reconocer en su actuar.

Nos encontramos frente a un círculo vicioso que no parece tener fin y a todas luces se trata de un ciclo que no es inocuo y que por tanto es necesario detener.

\footnotetext{
57 Información obtenida de la revisión de la sección "noticias" de la página web del Poder Judicial de Chile en el período 2011-2014: http://www.pjud.cl/noticias-del-poder-judicial.

58 La presente cita es consistente con lo indicado en la cita 52 y lo indicado por el abogado entrevistado respecto de la simpleza jurídica del área de familia y la preeminencia de factores interdisciplinarios como algo anómalo.
} 


\section{CONCLUSIONES}

1. El estudio y análisis de los sistemas de justicia reformados no solo debe ser realizado desde una perspectiva dogmática, sino que es igualmente necesario examinarlos desde una perspectiva empírica. Así, gracias a este enfoque que trasciende el texto de la ley y la jurisprudencia, es posible identificar problemas que afectan al funcionamiento del sistema e incluso la misma vigencia de las normas procesales.

2. Ahora bien, el presente trabajo se enfocó en examinar los tribunales de familia desde la perspectiva de sus operadores, en particular de los jueces de familia. Gracias a este enfoque no solo se logró detectar la existencia de labores que suponen problemas para los jueces (relaciones tensas con abogados particulares, no saber cómo escuchar a los niños, prácticas cuestionables al momento de dirigir audiencias y no saber trabajar con partes sin abogados), sino que fue posible identificar algunas de sus causas (desconfianza mutua entre jueces y abogados privados) y se logró caracterizar los desafíos que estos obstáculos suponen para los magistrados (éticos y de destrezas).

3. Todo lo anterior nos permite concluir que existen dinámicas disfuncionales en los tribunales de familia y que algunas de ellas tienen lugar en el contexto de las audiencias, cuando los jueces deben interactuar con otros usuarios del sistema. A este respecto no debe olvidarse que los sistemas judiciales suponen la coordinación y el trabajo conjunto de diversos actores y si la relación entre dichos actores presenta problemas, no es sorprendente que impacte eventualmente en el funcionamiento del sistema.

4. Esto necesariamente debe llevar a preguntarnos por las razones de dichos problemas y en el presente documento se esbozan dos hipótesis, ambas igualmente relevantes. Una posibilidad es que los problemas que los jueces de familia enfrentan deriven de déficits en su entrenamiento. La segunda hipótesis, más general y teórica, se refiere al prestigio que la justicia de familia tiene y cómo la comprensión de esta área del derecho como una poco legalista ("familia no es derecho") afecta las concepciones de aquellos que trabajan en ella y origina prácticas complejas que tienen la potencialidad de afectar al sistema mismo. Ambas hipótesis requieren de mayor estudio y quedará para trabajos futuros profundizar en ellas.

5. Los nuevos tribunales de familia han cumplido 10 años desde que abrieron sus puertas y es necesario continuar con su estudio con la finalidad de lograr su consolidación. Se espera que el presente trabajo contribuya a ello.

\section{BIBLIOGRAFÍA CITADA}

Azócar, María José (2014): Gendered Legal Expertice: Court Reforms and Judicial Policy Making in Chile (Wisconsin, University of Wisconsin, documento no publicado en poder del autor).

Azócar, María José, Casas, Lidia y Vargas, Macarena (2008): Mediación Familiar y Género. Cuadernos de Análisis Jurídico 18 (Santiago, Ediciones Universidad Diego Portales).

Biblioteca del Congreso Nacional de Chile (2005): Historia de la ley 19.968 que creó los Tribunales de Familia. 
Ballesteros, Rubén (2012): "Discurso de inauguración del Juzgado de Familia de Talca". Disponible en: <http://www.pjud.cl/documents/10179/65441/Discurso+con+motivo+ de+la+inauguraci\%C3\%B3n+del +Juzgado+de+Familia+de+Talca+\%2810+de+agosto+ de+2012\%29.pdf/645396df-a528-4dee-87b1-b6fe640149bd> Fecha de consulta: 25 de septiembre de 2014.

BaraOna, Jorge (2010): "La Cultura Jurídica Chilena: Apuntes históricos, tendencias y desafíos", Revista de Derecho de la Pontificia Universidad Católica de Valparaíso, Vol. XXXV: pp. 427-448.

Bengoechea, María Zaíra (2010): "Presentación de la presidente de la Asociación de Consejeros Técnicos en Jornada de Reflexión La Serena octubre de 2010”. Disponible en: <http://www.pjud.cl/documents/10179/190209/9.Presentaci\%C3\%B3n+de+la+ presidenta+de+la+Asociaci $\% \mathrm{C} 3 \% \mathrm{~B} 3 \mathrm{n}+\mathrm{de}+$ Consejeros+T\%C3\%A9cnicos $\% 2 \mathrm{C} \% 20$ Mar\%C3\%ADa+Zaira+Bengoechea+A.pdf/e04bfd0a-291c-4765-a140-e4f0b2da72db>

Bryman, Alan y Teevan, James (2005): Social Research Methods (Canada, Oxford).

Carreño Seaman, Héctor (2012): "Actividades de la Unidad de apoyo a la Reforma de Familia de la Corte Suprema al año 2011", Oficio 08/2012, 24 de enero de 2012. Disponible en: <http://www.pjud.cl/documents/10179/67750/12.-+Unidad+de+Apoyo+al+sis tema+de+Familia.pdf/789cf06a-6840-4431-9ce0-378e4ba22dc2?version=1.0> Fecha de consulta: 16 de agosto de 2014.

Carreño Seaman, Héctor (2013): "Minuta trabajo realizado por la Unidad de apoyo a la justicia de familia en 2012", Oficio $N^{o} 4 / 2013$, documento en poder del autor.

Carretta Muñoz, Francesco (2013): "Sobre la oralidad de los procesos: una perspectiva desde los tribunales de familia hacia la reforma procesal civil”, en Ansaldi BALTAZAR, Octavio y Chandía Olivares, Sebastián (edit.), Estudios de Derecho de la Judicatura. Actas del 1er y 2do Congreso Estudiantil de Derecho de la Judicatura (2011-2012) (Valparaíso, Universidad Católica de Valparaíso) pp. 199-203.

Carretta Muñoz, Francesco (2014): "La desformalización del proceso judicial de familia e infancia", Revista de Derecho de la Pontificia Universidad Católica de Valparaíso, Vol. XLII: pp. 481-495.

CASAs, Lidia et al. (2006): "El funcionamiento de los nuevos tribunales de familia. Resultados de una investigación exploratoria”. Disponible en: http://www.reformasprocesales. udp.cl/INVESTIGACION/Informe_tribunales_familia_udp2.pdf.

CASAs, Lidia y OlEa, Helena (2014): “Trabajadoras de casa particular: Invisibilizadas y discriminadas", en Informe Anual de Derechos humanos en Chile 2014 (Santiago, Centro de Derechos Humanos Universidad Diego Portales) pp. 109-155.

Casas, Lidia, Riveros, Francisca y Vargas, Macarena (2012): Violencia de Género y la Administración de Justicia (Santiago, SERNAM).

Correa, Paula y Vargas, Macarena (2011): "La voz de los niños en la Justicia de Familia de Chile", Ius et Praxis, vol. 17, núm. 1: pp. 177-203.

Corte Suprema de Chile (2009): "Cuenta Pública Unidad de Apoyo a la Reforma de Familia”.

Darbyshire, Penny (2011): Sitting in judgment. The working lives of judges (Reino Unido, Hart Publishing). 
DucE, Mauricio (2013): "La prueba pericial y su admisibilidad en el nuevo proceso civil", en Aguirrezabal Grunstein, Maite (coord.), Justicia Civil: perspectiva para una reforma en la legislación chilena (Santiago, Universidad de los Andes) pp. 114 y ss.

Fix-Fierro, Héctor, Friedman, Lawrence y Pérez-Perdomo, Rogelio (2003): Culturas Jurídicas Latinas de Europa y América en tiempos de Globalización (México, UNAM).

Eekelaar, John y Maclean, Mavis (2013): Family Justice. The work of family judges in uncertain times (Reino Unido, Hart Publishing).

Escuela Judicial de España. Servicio de Formación continua (2012): "Conclusiones. Encuentro con la abogacía especializada en Derecho de Familia”. Disponible en: <http:// www.scaf.cat/downloads/en12101.pdf>

Fuentes, Claudio, Marín, Felipe y Ríos, Erick (2010): "Funcionamiento de los Tribunales de Santiago", en Cabezón, Andrea (coord.), Reformas a la Justicia en América Latina. Experiencias de Innovación (Santiago, Centro de Estudios de Justicia de las Américas) pp. 371-459.

GaínZA, Álvaro (2006): "La entrevista en profundidad individual”, en CANALES, Manuel (coord.), Metodologías de investigación social (Santiago, LOM Ediciones, Ciencias Humanas) pp. 219-263.

García, Pedro (2012): "Herramientas de gestión judicial para los juzgados de familia", Revista de Derecho de la Universidad Católica de la Santísima Concepción, vol. 25, 2012-1: pp. 155-181.

GonZÁlez, Felipe (2003): Cultura Judicial y Enseñanza del Derecho en Chile: una aproximación (Santiago, Universidad Diego Portales).

Hunter, Iván (2011): Las potestades probatorias del juez de familia (Santiago, LegalPublishing).

KoHen, Beatriz (2008): "Family Judges in the city of Buenos Aires: a view from within", International Journal of the Legal Profession, vol. 15:1-2: pp. 111-122.

KRITZER, Herber (2004): Risks, reputations and rewards (Estados Unidos, Stanford University Press).

Macaulay, Stewart (1985): "An empirical view of contract", Revista Chilena de Derecho, vol. 12, No. 3: pp. 429-441.

MoOrHeAD, Richard (2007): "The passive arbiter: Litigants in Person and the challenge to Neutrality”, Social \& Legal Studies, vol. 16-3: pp. 405-424.

Palomo Vélez, Diego y Matamala Souper, Pedro (2011): “Juez y Parte. El compromiso espiritual del juez en el interrogatorio de testigos en el juicio laboral y sus necesarios limites", Ius et Praxis, vol. 17-2: pp. 485-504.

RiEgo, Cristian (2013): "El sistema de "Case management" y su aplicación al contexto Chileno" (Documento inédito en poder del autor).

Ríos, Erick (2013): "La oralidad en los procesos civiles en América Latina. Reflexiones a partir de una observación práctica, en Centro de Estudios de Justicia de las Américas (edit.), Aportes para un diálogo sobre el acceso a la justicia y la reforma civil en América Latina (Santiago, Centro de Estudios de Justicia de las Américas) pp. 95-166.

SiLva et al. (2007): "Estudio exploratorio sobre el funcionamiento de la oralidad en los tribunales de familia de la Región Metropolitana” en CABEzón, Andrea (coord.), Justicia 
Civil: Perspectivas para una Reforma en América Latina (Santiago, Centro de Estudios de Justicia de las Américas) pp. 131-180.

Thomas, Cheryl (2006): "Review of Judicial Training and Education in other jurisdictions”. Disponible en: http://www.ucl.ac.uk/laws/judicial-institute/docs/Judicial_Training_Report.pdf.

\section{NORMAS CITADAS}

Ley No 19.968 (30/08/2004), que crea los Tribunales de Familia.

Ley No 20.286 (15/09/2008), que introduce modificaciones orgánicas y procedimentales a la ley No 19.968, que crea los tribunales de familia.

ACTA 98-2009 (20/05/2009), Auto acordado sobre gestión y administración en tribunales de familia. 
